\title{
Hurricane Mitch: Impacts on Mangrove Sediment Elevation Dynamics and Long-term Mangrove Sustainability
}

Donald R. Cahoon

Geological Survey (U.S.)

Philippe Hensel

National Wetlands Research Center (U.S.)

John M. Rybczyk

Western Washington University, john.rybczyk@wwu.edu

Brian Christopher Perez

Geological Survey (U.S.)

Follow this and additional works at: https://cedar.wwu.edu/esci_facpubs

Part of the Sustainability Commons

\section{Recommended Citation}

Cahoon, Donald R.; Hensel, Philippe; Rybczyk, John M.; and Perez, Brian Christopher, "Hurricane Mitch: Impacts on Mangrove Sediment Elevation Dynamics and Long-term Mangrove Sustainability" (2002). Environmental Sciences Faculty and Staff Publications. 49.

https://cedar.wwu.edu/esci_facpubs/49

This Book is brought to you for free and open access by the Environmental Sciences at Western CEDAR. It has been accepted for inclusion in Environmental Sciences Faculty and Staff Publications by an authorized administrator of Western CEDAR. For more information, please contact westerncedar@wwu.edu. 


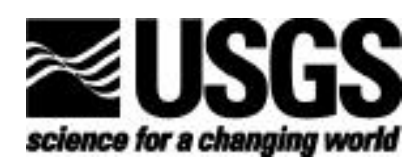

\section{Hurricane Mitch: Impacts on Mangrove Sediment Elevation Dynamics and Long-Term Mangrove Sustainability}

By Donald R. Cahoon, Philippe Hensel, John Rybczyk, and Brian C. Perez

USGS Open File Report

OFR 03-184

U.S. Department of the Interior

U.S. Geological Survey 
This report is preliminary and has not been reviewed for conformity with U.S. Geological Survey editorial standards

Any use of trade, product, or firm names is for descriptive purposes only and does not imply endorsement by the U.S. Government.

Suggested citation:

Cahoon, D.R., Hensel, P., Rybczyk, J. and Perez, B.C., 2002, Hurricane Mitch: impacts on mangrove sediment elevation dynamics and long-term mangrove sustainability: USGS Open File Report 03-184, 75 p. 


\title{
USGS ACTIVITY B6 AND B7
}

\section{Hurricane Mitch: Impacts On Mangrove Sediment Elevation Dynamics And Long-Term Mangrove}

\author{
Sustainability
}

By

Donald R. Cahoon ${ }^{1}$, Philippe Hensel², John Rybczyk ${ }^{3}$, and Brian C. Perez ${ }^{1}$

\footnotetext{
${ }^{1}$ USGS, National Wetlands Research Center, Lafayette, LA, USA

${ }^{2}$ Johnson Controls Inc., National Wetlands Research Center, Lafayette, LA, USA

${ }^{3}$ Western Washington University, Huxley College of Environmental Science,

Bellingham, WA, USA
}

October 4, 2002 


\section{Contents}

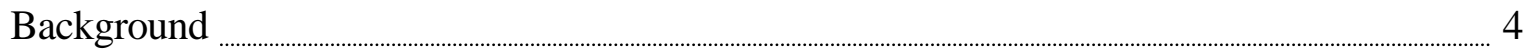

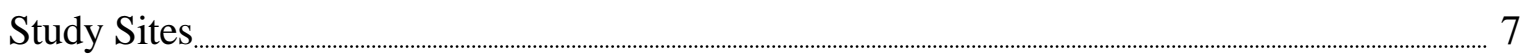

Materials and Methods $\ldots$

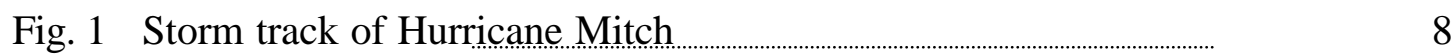

Table 1 Depth of Hurricane Mitch-related sediment deposits in mangrove forests of Honduras and Guatemala $\ldots$

Fig. 2 Map of Guanaja showing area of study 10

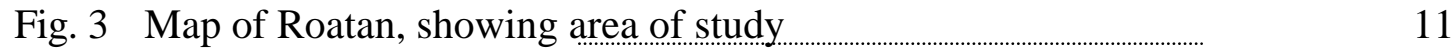

Fig. 4 Photographs of Bay Island study sites $\ldots$

Fig. 5 Conceptual diagram of the Rod SET and Marker Horizons $\quad 14$

Fig. 6 Deployment of the Rod SET in Punta de Manabique 15

Fig. 7 Deployment of marker horizons in the Gulf of Fonseca 17

Fig. 8 Measurement of soil vertical accretion in an organic sediment 18

Fig. 9 Map showing locations of study sites in Punta de Manabique 19

Fig. 10 Photographs of study sites in Punta de Manabique 20

Fig. 11 Map of the Gulf of Fonseca, showing area of study 22

Fig. 12 Photographs of study sites in the Gulf of Fonseca 23

Relative Elevation Model

Statistical Analyses

Results

Bay Islands

Fig. 13 Vertical accretion in Bay Island shoreline mangroves 28 


\section{Contents (cont.)}

Fig. 14 Vertical accretion in Bay Island interior mangroves

Fig. 15 Soil core showing accretion in Guanaja $\quad 30$

Fig. 16 Surface elevation in Bay Island interior mangroves $\ldots$

Fig. 17 Surface elevation in Bay Island shoreline mangroves

Table 2 Soil surface elevation in low impact mangrove site 1 in Roatan 35

Table 3 Soil surface elevation in low impact mangrove site 2 in Roatan

Table 4 Soil surface elevation in a medium impact mangrove site in Roatan 37

Table 5 Soil surface elevation in a high impact mangrove site in Guanaja 38

Fig. 18 Simulated and observed sediment organic matter over soil depth in Guanaja. 41

Fig. 19 Comparison of simulated sediment elevation trajectories in Guanaja 42

Table 6 Simulated effects of Hurricane Mitch on mangrove sediment dynamics in Guanaja

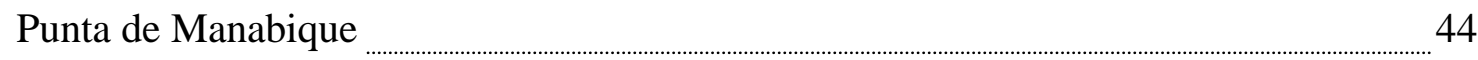

Fig. 20 Vertical accretion in Punta de Manabique $\quad 45$

Fig. 21 Soil core showing accretion in Punta de Manabique 46

Fig. 22 Surface elevation in Punta de Manabique 47

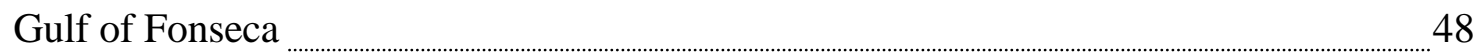

Fig. 23 Vertical accretion in shoreline mangroves of Gulf of Fonseca

Fig. 24 Vertical accretion in interior mangroves of Gulf of Fonseca

Fig. 25 Surface elevation in shoreline mangroves of Gulf of Fonseca

Fig. 26 Surface elevation in interior mangroves of Gulf of Fonseca) 


\section{Contents (cont.)}

Discussion $\quad 55$

Bay Islands

Punta de Manabique $\quad 59$

Gulf of Fonseca

Acknowledgments $\quad 62$

Literature Cited

Appendix: Sediment Elevation Model Methodology $\quad 68$ 


\section{Background}

Hurricane Mitch left three very different impacts on mangroves in the coastal zone of Central America. First, in the Caribbean, direct wind and flood-induced mangrove mortality was seen in the Bay Islands. Second, wave-induced erosion of beaches and subsequent sediment deposition buried mangrove forests of Punta de Manabique, Guatemala. Finally, along the Pacific coast, some mangroves of the Gulf of Fonseca were buried under up to $100 \mathrm{~cm}$ of sediments eroded from uplands and carried down slope by river flooding. Each of these three impacts left a different footprint on the mangrove communities, and these communities are expected to follow different recovery trajectories. These time-dependent responses will lead to different rates of success at reaching prehurricane conditions and imply differences in mangrove forest sustainability in face of a constantly changing environment. Rising sea level, for example, might make Caribbean mangroves more susceptible to hurricane-induced elevation deficits.

The long-term stability of mangrove forests depends in part on the ability of mangrove sediment surfaces to keep pace with sea-level rise. The Bay Islands of Honduras are far from continental sources of sediment, and the mangrove forests therefore have primarily organic soils. Mangrove root growth and litter fall are the main contributors to the fibrous soil matrix. Since these materials are constantly decomposing and turning over, continual addition of organic matter is required for the mangrove sediment surface to maintain its elevation. In the wake of Hurricane Mitch, the process of sediment elevation 
maintenance is placed into jeopardy for those mangrove forests that suffered high mortality.

Little is known about the balance between production and decomposition of soil organic matter in the maintenance of mangrove sediment elevation. Evidence from a study in Florida has suggested that extensive mangrove mortality in a carbonate setting may lead to sediment collapse and the conversion of previous mangrove forests to mudflats (Wanless and others, 1994). This is particularly alarming for an area such as Guanaja, which sustained a high rate of mangrove tree mortality (95\%) due to Hurricane Mitch (DeSomviele, 1999). The case of Guanaja is made worse by the fact that probable sources of mangrove propagules are very remote (e.g., the coast of Mosquitia, Honduras). Ocean currents run east to west, effectively isolating Guanaja from its nearest neighbor, Roatan. If the sediment surface collapses from oxidation and compaction of the peat before new plants can recolonize the area, natural recovery of previous mangrove forests would likely be impossible given current and predicted rates of increasing sea level.

A very important feature of mangrove forests is their ability to trap and bind sediment within their extensive root structures. Under a moderate sedimentation rate, a mangrove forest will accelerate the process of land formation. Too much sedimentation, on the other hand, can lead to mangrove mortality as the sediments asphyxiate the respiratory structures (e.g., lenticels and aerenchyma), which mangroves have developed to allow for gas exchange within the roots (Ellison 1998). In the Gulf of Fonseca, shear from the floodwaters' solid discharge and massive sedimentation caused both defoliation of 
mangrove canopies and asphyxiation of mangrove roots, respectively. The outcome was large expanses of mangrove mortality. Since the accreted surfaces are now at a higher elevation than before the hurricane, flooding frequencies are reduced along with the opportunities for propagule recruitment. Without sufficient root growth, these accreted surfaces may be unstable and erode over time, complicating further recovery. Such continued reworking of Hurricane Mitch sediments would represent continued, long-term chronic impacts to the coastal environment.

The main issues this study addresses are:

1) What is the sediment elevation response of mangrove forests to three different mechanisms of hurricane-related impacts? How do the responses change over different intensities of impact? Are the effects homogenous across the intertidal zones?

2) What are the long-term impacts to mangrove forest recovery and sustainability in the face of sea-level rise across the three different impact types? Are these impacts constant across intertidal zones as well?

a) Will mangrove sediments collapse in the Bay Islands?

b) Are newly accreted surfaces in Guatemala and the Gulf of Fonseca stable features, or do they represent future sources of remobilized sediment with potentially chronic impacts to mangrove forests or adjacent seagrass communities? 


\section{Study Sites}

Three coastal mangrove regions were chosen to represent the three mechanisms of hurricane-related impacts (wind, wave and sedimentation): The Bay Islands of Roatan and Guanaja, Honduras (wind impacts), Punta de Manabique, Guatemala (wave and sediment impacts) and the Gulf of Fonseca, Honduras (sediment burial; fig. 1). The Bay Islands and Punta de Manabique correspond to regions directly affected by the passage of the hurricane within the coastal environment. The Gulf of Fonseca corresponds to a region that received the accumulated indirect effects of extreme rainfall, erosion, landslide and debris flows within the larger watershed. Not surprisingly, storm-related sedimentation patterns differed importantly among the three areas (table 1; McKee and McGinnis, 2002). There were negligible sediment deposits in the Bay Island forests where most of the damage was caused by winds and storm surge. At Punta de Manabique, storm waves toppled trees, and eroded the beach sand and deposited it in mangrove forests located behind the beach. In the Gulf of Fonseca, large quantities of silts and clays eroded from uplands were deposited in the mangrove forests.

\section{Materials and Methods}

In the Bay Islands, mangrove forests were chosen to represent low, medium, and high levels of wind and flooding impact. Both shoreline and interior forests were chosen within each impact level, resulting in six combinations of impact levels and intertidal zones. The high impact area was limited to Guanaja, where three replicate shoreline and 
Figure 1. Map of Honduras showing the track of Hurricane Mitch in relation to the three geographic areas (circled in red) where a study of mangrove sediment surface responses to Hurricane Mitch was conducted between January 2000 and August 2001: the Bay Islands of Roatan and Guanaja (Honduras), Punta de Manabique (Guatemala) and the Gulf of Fonseca (Honduras).

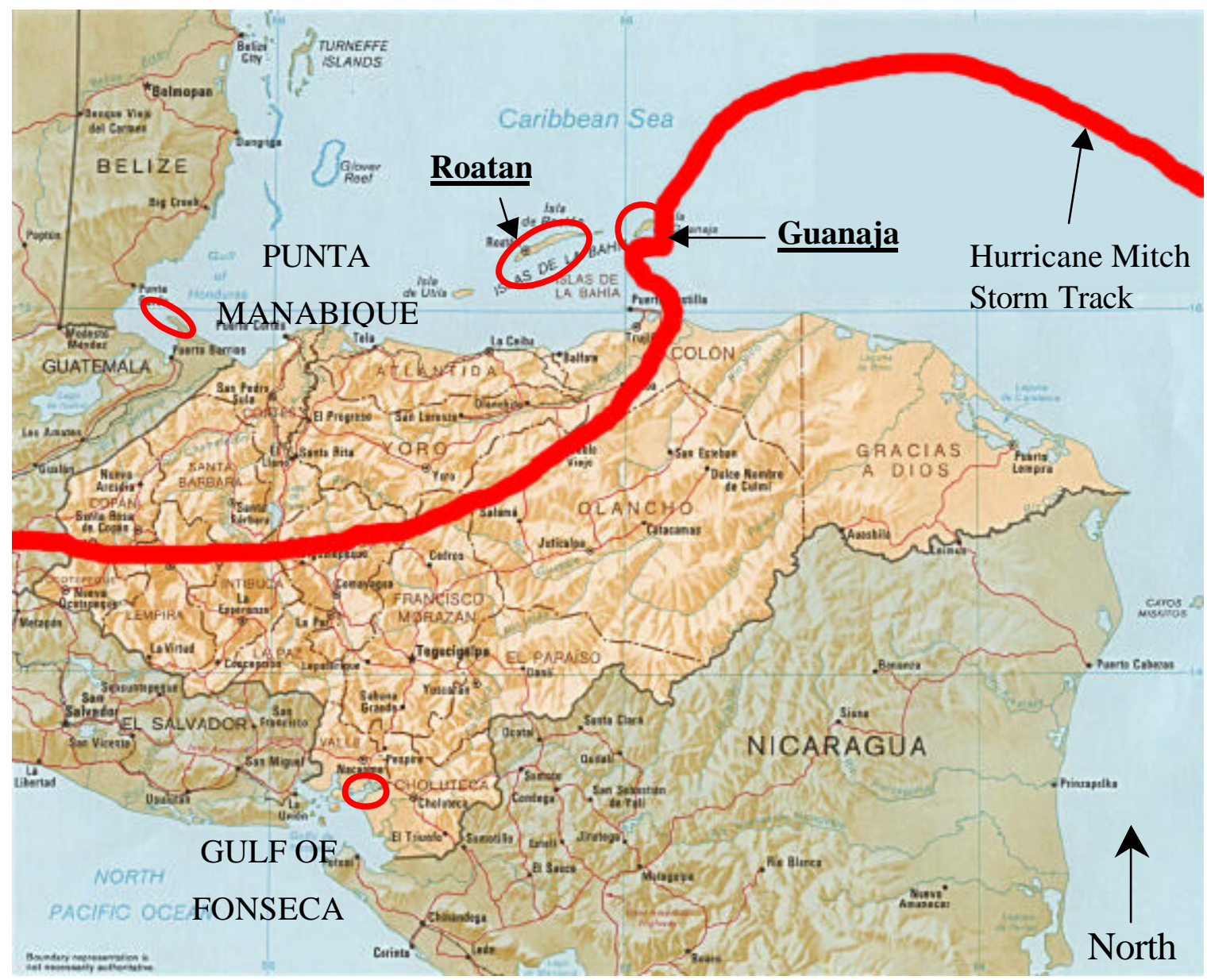


Table 1. Depth of Hurricane Mitch-related sediment deposits in mangrove forests in Honduras and Guatemala, from McKee and McGinnis, 2002. Data from Honduras obtained in January 2000, 14 months after the storm. Data from Guatemala obtained in late August 2000, 22 months after Hurricane Mitch. Units of depth given in centimeters.

\begin{tabular}{|c|c|c|c|}
\hline \multirow[b]{2}{*}{ REGION } & \multicolumn{2}{|r|}{ Intertidal zone } & \multirow[b]{2}{*}{ INTERIOR } \\
\hline & IMPACT LEVEL & SHORELINE & \\
\hline Bay Islands & Low & 0 & 0 \\
\hline \multirow[t]{2}{*}{ (Honduras) } & Medium & $2^{1}$ & $4(3-5)^{1}$ \\
\hline & High & $2^{1}$ & 0 \\
\hline \multirow[t]{2}{*}{ Guatemala } & Low & 0 & \\
\hline & High & $81(61-122)^{2}$ & \\
\hline \multirow{3}{*}{$\begin{array}{l}\text { Gulf of Fonseca } \\
\text { (Honduras) }\end{array}$} & Low & 0 & 0 \\
\hline & Medium & $16(7-25)^{3}$ & $91(78-97)^{3}$ \\
\hline & High & $44(36-50)^{3}$ & $13(9-16)^{3}$ \\
\hline
\end{tabular}


Figure 2. Map of Guanaja (Bay Islands, Honduras), showing the area of Mangrove Bight where mangrove sediment surface responses to high hurricane impacts were studied (circled in red).

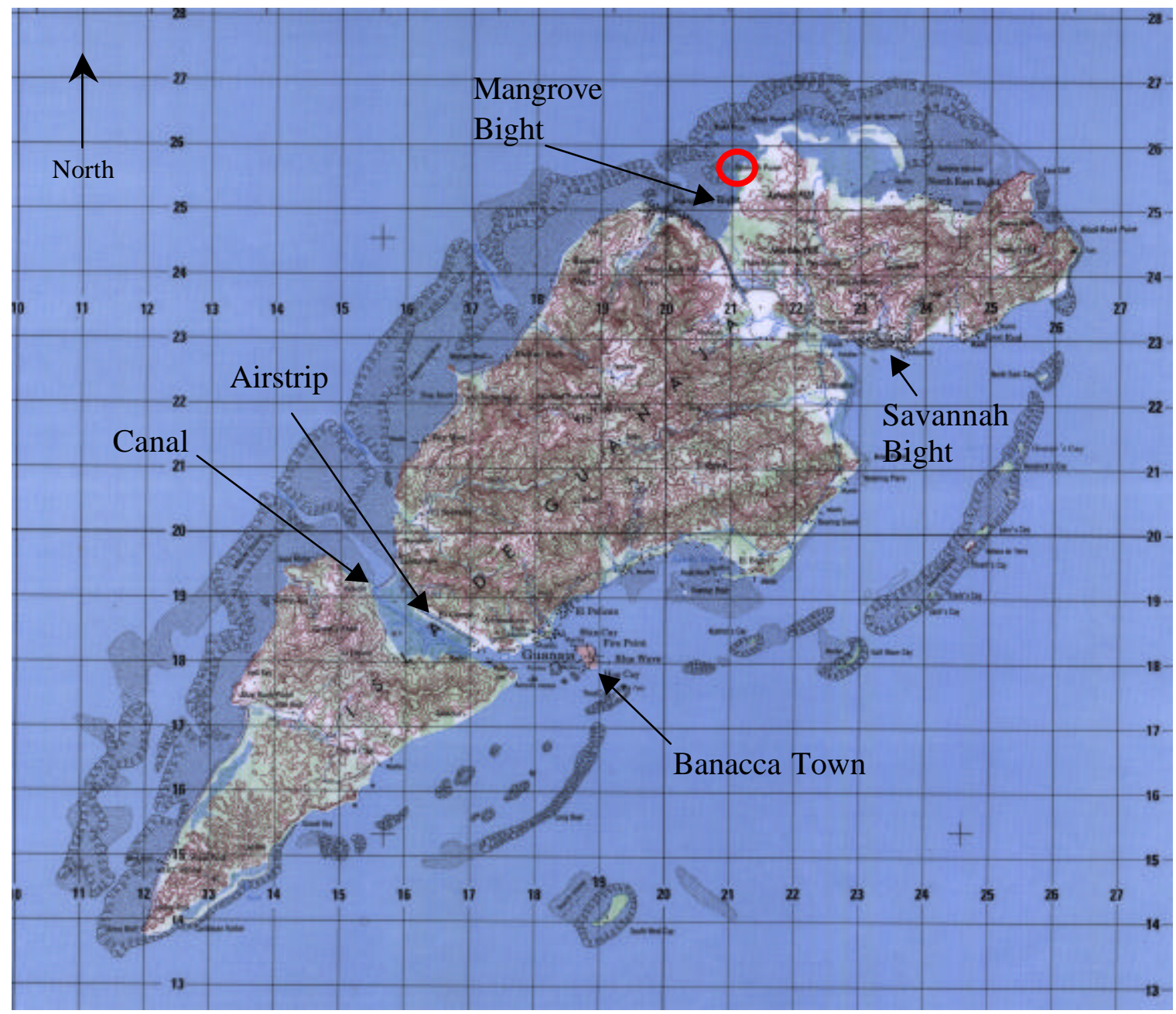


Figure 3. Map of Roatan (Bay Islands, Honduras), showing the location of the area where mangrove sediment surface responses to low and medium hurricane impacts were studied (Santa Elena mangroves). The north shore mangroves (circled in red) received wind and wave-induced damage from Hurricane Mitch.

The south shore mangrove forest (circled in purple) was relatively protected from these effects.

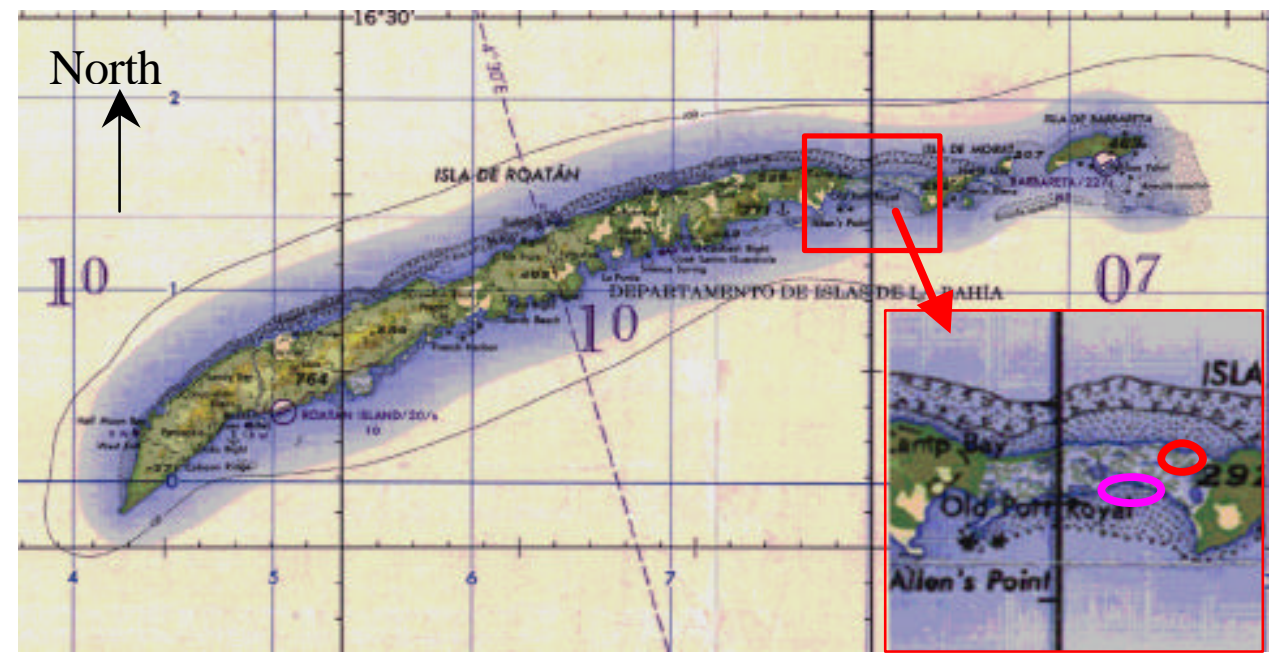


Figure 4: Photographs from six mangrove forests in the Bay Islands, Honduras, which were investigated for Hurricane Mitch-related impacts: A) low impact shoreline (south shore, Roatan); B)low impact interior (south shore, Roatan); C) medium impact shoreline (north shore, Roatan); D) medium impact interior (north shore, Roatan); E) high impact shoreline (Guanaja); F) high impact interior (Guanaja).

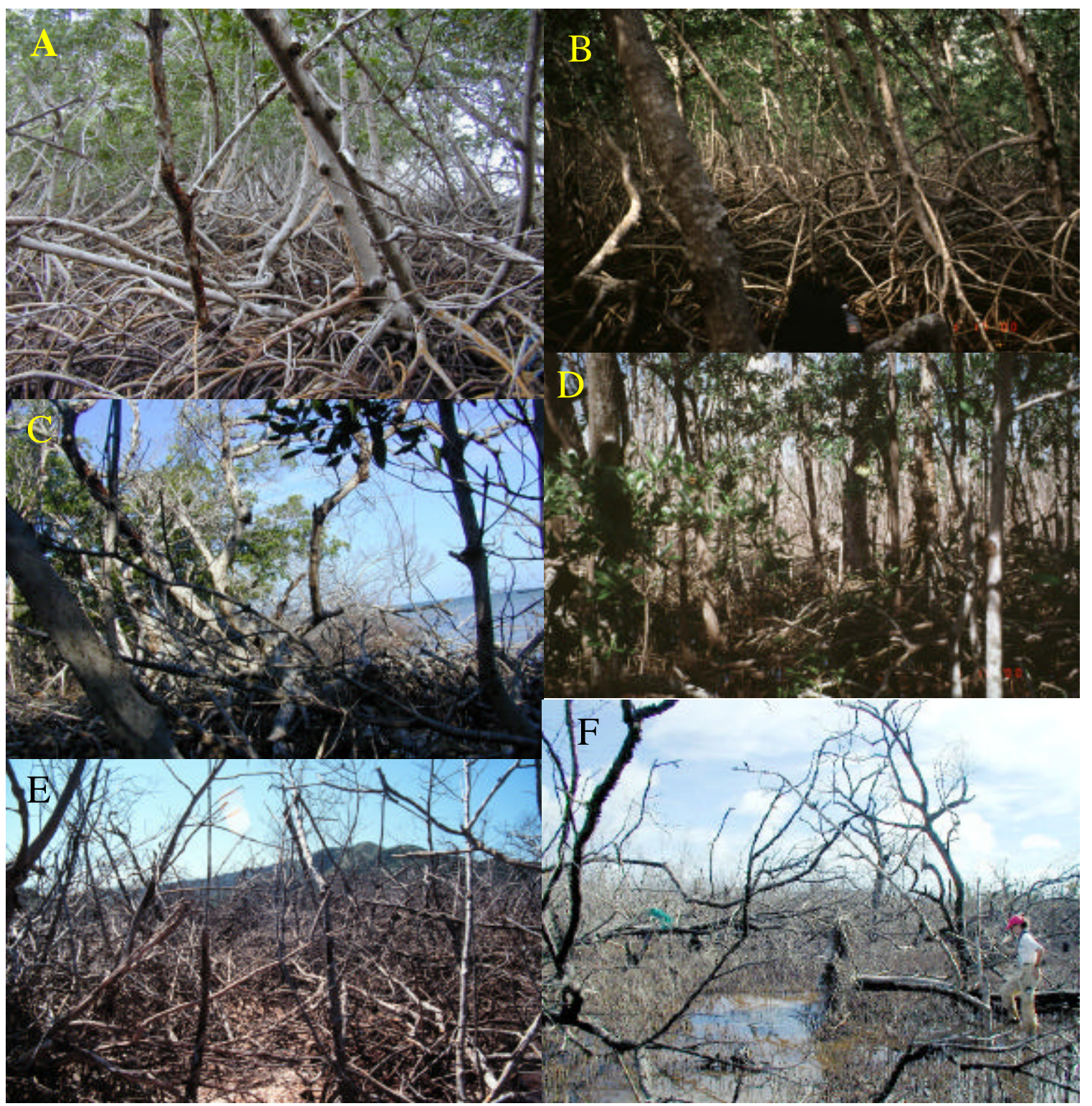


three replicate interior plots were randomly established within the Mangrove Bight area (16 $30^{\prime} \mathrm{N}, 85^{\circ} 51^{\prime} \mathrm{W}$; fig. 2$)$. A low and a medium impact area were identified along the south $\left(16^{\circ} 25^{\prime} \mathrm{N}, 86^{\circ} 14^{\prime} \mathrm{W}\right)$ and north $\left(16^{\circ} 25^{\prime} \mathrm{N}, 86^{\circ} 13^{\prime} \mathrm{W}\right)$ shores, respectively, of the Santa Elena mangroves (Roatan; fig. 3). As in Guanaja, three replicate shoreline and three replicate interior mangrove forest plots were randomly established within both the low and medium impact areas. A total of eighteen mangrove forest plots were thereby established in the Bay Islands (fig. 4).

In each plot, a single Rod Surface Elevation Table, or Rod SET, (Cahoon and others 2002) station was established to monitor changes in sediment elevation over time (fig. 5). Stainless steel benchmark rods (in $4 \mathrm{ft}$. sections) were sequentially inserted into the sediment until refusal, using a hand-held pile driver. A stainless steel collar was then fixed onto the last rod section, which would serve as the attachment point for the Rod SET. Upon deployment, the Rod SET is fitted to the collar (held in place with clamps) and leveled in two dimensions. Nine labeled fiberglass pins are inserted into each of nine corresponding holes along the horizontal arm of the Rod SET, and each pin carefully is lowered until it contacts the sediment surface. The distance from the horizontal arm of the Rod SET to the top of each pin corresponds to the elevation of the sediment (fig. 6). The Rod SET collar allows for a total of eight positions to be taken in a circle around the benchmark rod (each 45 degrees apart). To avoid altering measured sediment surfaces, only five of the eight positions were read, corresponding to a semicircle in front of a path of approach. 
Figure 5. A conceptual diagram showing that portion of the sediment profile measured by the Rod Surface Elevation Table and the marker horizon. Shallow subsidence is calculated as vertical accretion minus elevation change. Note: the average thickness of the storm deposit varied from 0 to $91 \mathrm{~cm}$ among the different study sites (table 1).

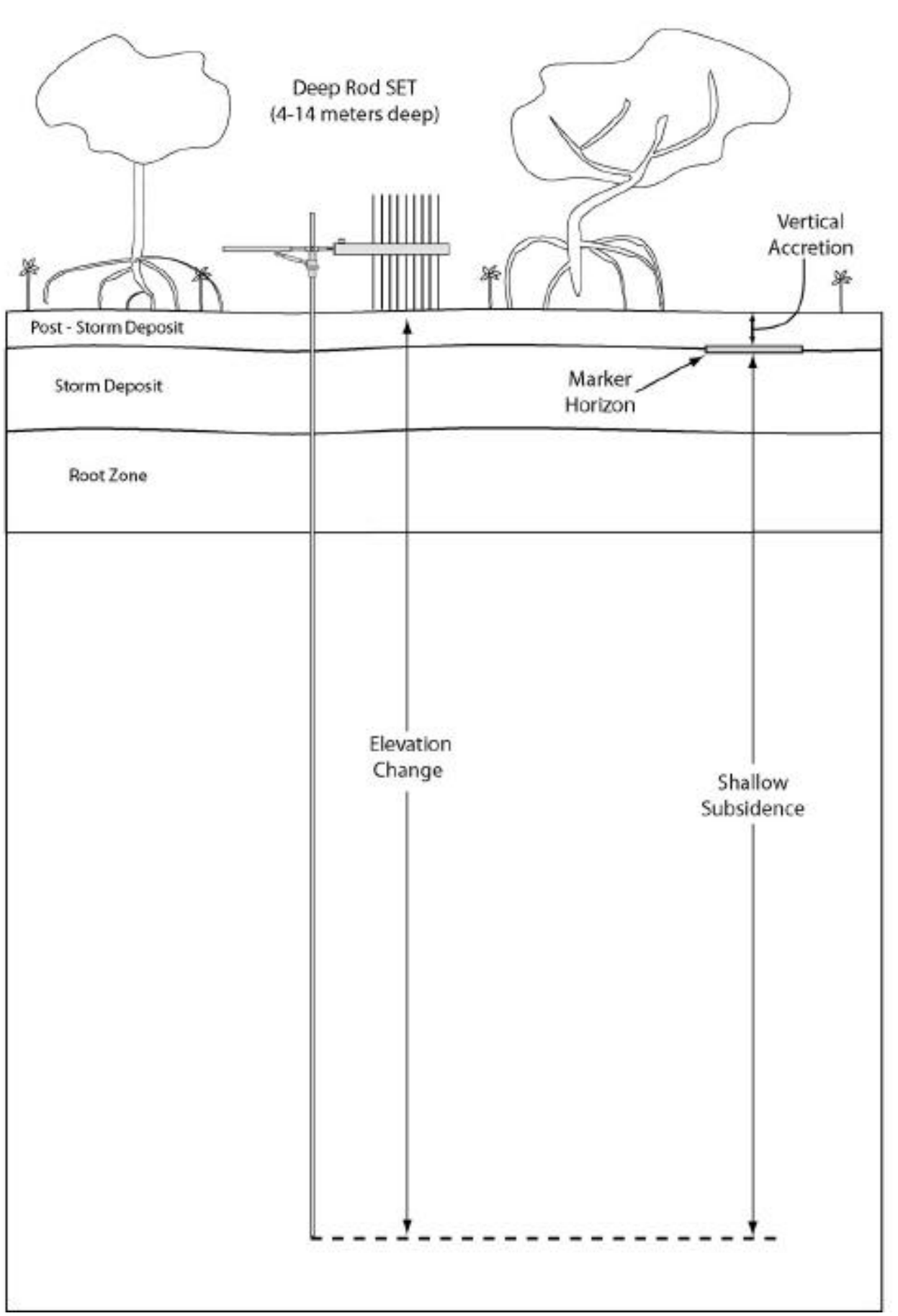


Figure 6. Deployment of the Rod Surface Elevation Table in mangrove sites in Punta de Manabique (photograph A; Guatemala) and the Gulf of Fonseca (photograph B; Honduras).

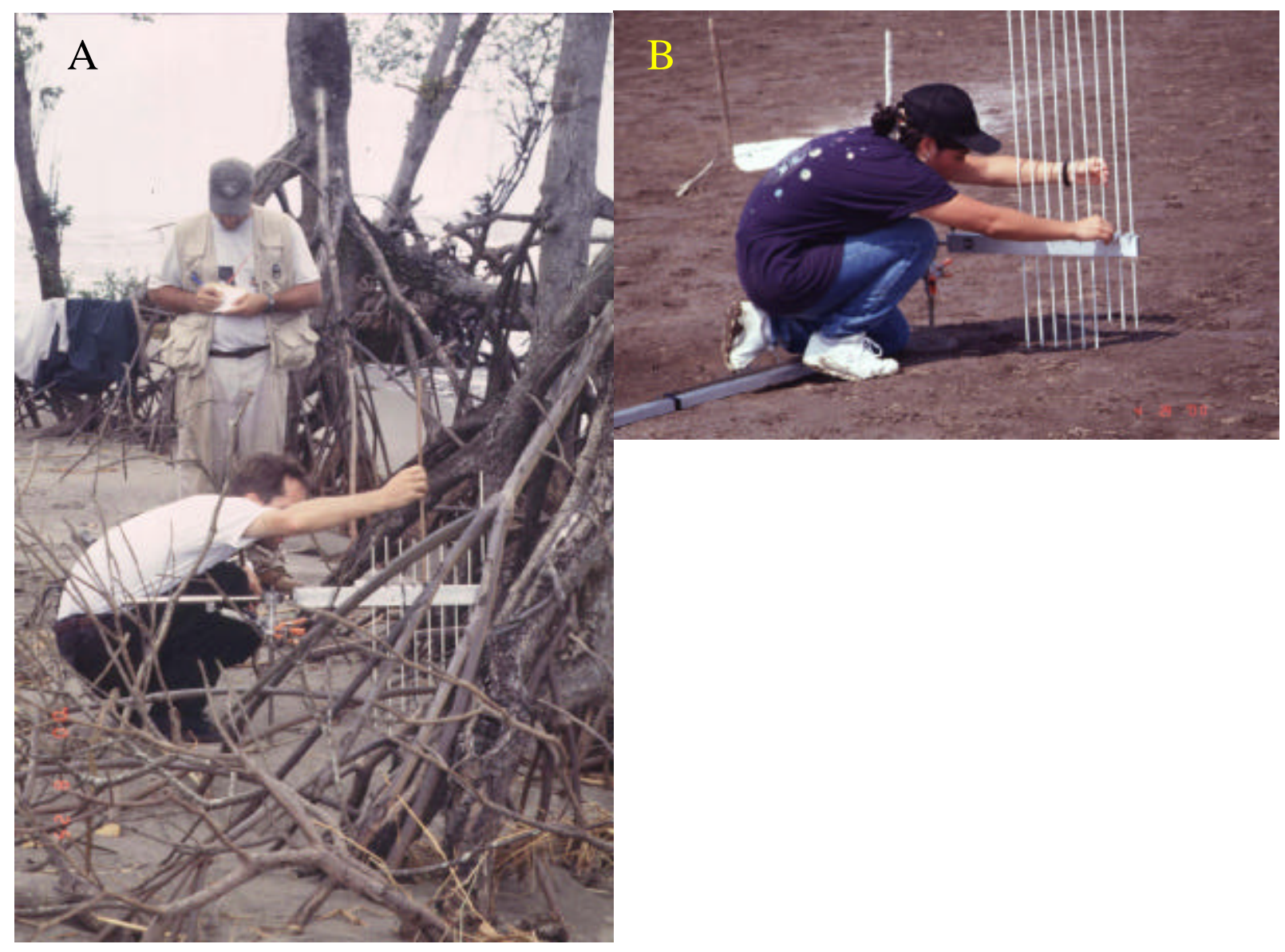


The Rod SET measures all processes affecting sediment elevation over the depth of the rod benchmark (often up to $10 \mathrm{~m}$ ). To separate belowground processes such as compaction, subsidence, root production, and sediment shrinking/swelling from the aboveground process of accretion, marker horizon plots were established in the vicinity of each Rod SET station (fig. 7). Three replicate $0.25 \mathrm{~m}^{2}$ markers (local beach sand) were laid at the same time that the baseline Rod SET readings were taken (May 4-7, 2000). Rod SET stations and marker horizons were initially read in early May 2000, with sequential readings taken in August 2000 and January, April, and August 2001. Reading the markers involved taking one or more short cores from each marker surface and making multiple measurements of depth to the marker within each core (fig. 8). Misses were recorded, and generally only one core was taken per horizon. The resulting experimental design was a repeated measures treatment design, with the six impact-by-zone treatment combinations measured sequentially over time. Impact levels and mangrove zones were assigned as a completely randomized design (CRD) with a nested error structure (pins, positions/marker horizons, plots). Plots were the error term for the factorial.

At Punta de Manabique, mangrove forests were chosen to represent high and low waverelated hurricane impacts. Two impact levels were identified: the high impact area was on the northern (exposed) coast of Manabique $\left(15^{\circ} 49^{\prime} \mathrm{N}, 88^{\circ} 24^{\prime} \mathrm{W}\right)$; the low impact area was located in Bahía de Graciosa, on the protected side of the Manabique peninsula $\left(15^{\circ} 52^{\prime} \mathrm{N}, 88^{\circ} 31^{\prime} \mathrm{W}\right.$; fig. 9). Only shoreline mangroves were common to both impact levels, so three replicate plots were randomly chosen within each impact level, for a total of six plots in Punta de Manabique. In Bahía de Graciosa, two plots were located along 
Figure 7. Deployment of feldspar and calcium carbonate marker horizons in the dwarf mangrove forests of the Conchalitos estuary damaged by Hurricane Mitch (Gulf of Fonseca, Honduras; April 2000). Three replicate $0.25 \mathrm{~m}^{2}$ horizons were randomly placed within the vicinity of the Rod SET to measure vertical accretion.

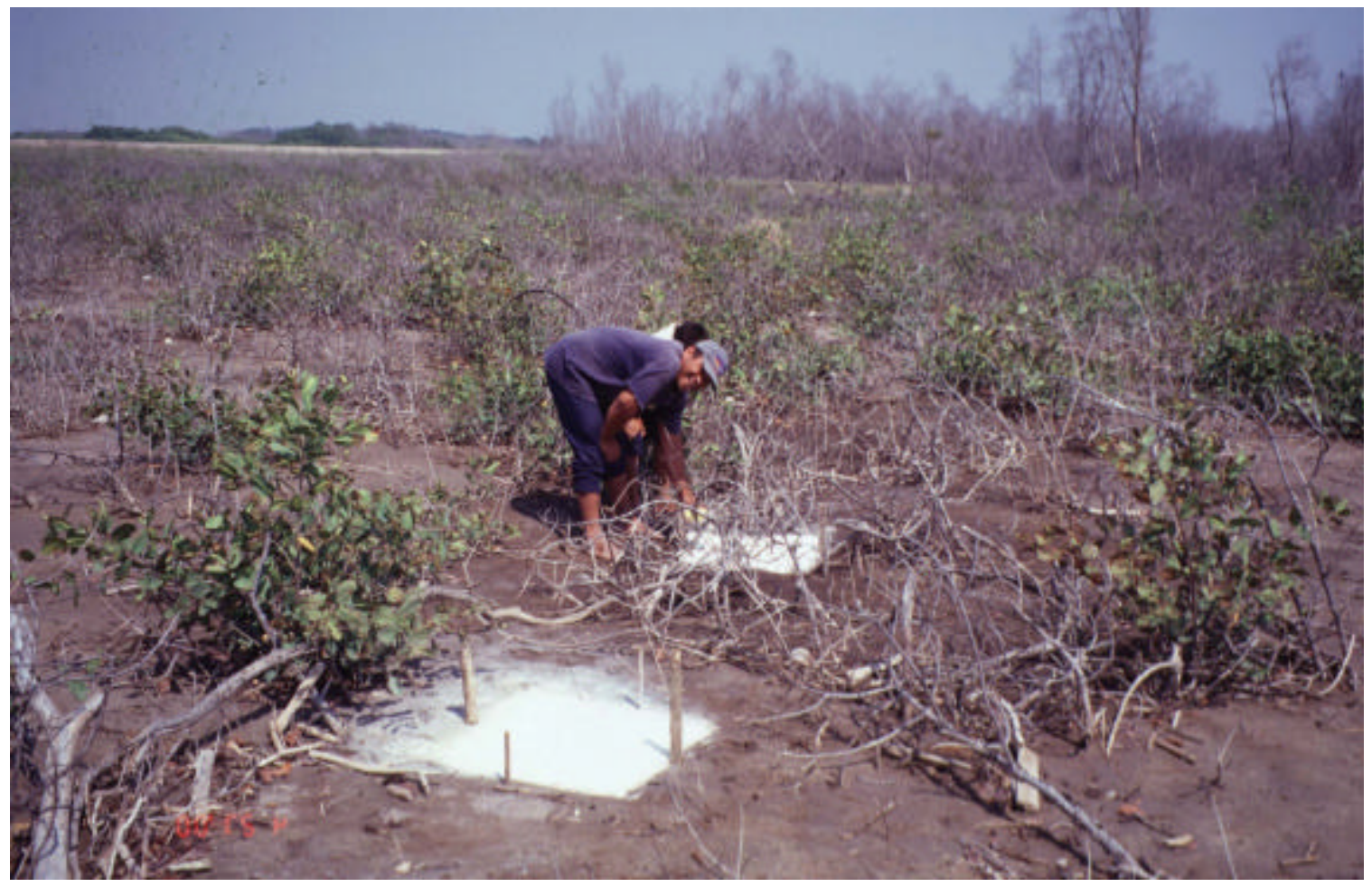


Figure 8. Measurement of soil vertical accretion in an organic sediment (Roatan, Bay Islands, Honduras). Accretion is measured as the amount of material accumulated on top of a marker horizon (in this case, a sand lens at the tip of the knife).

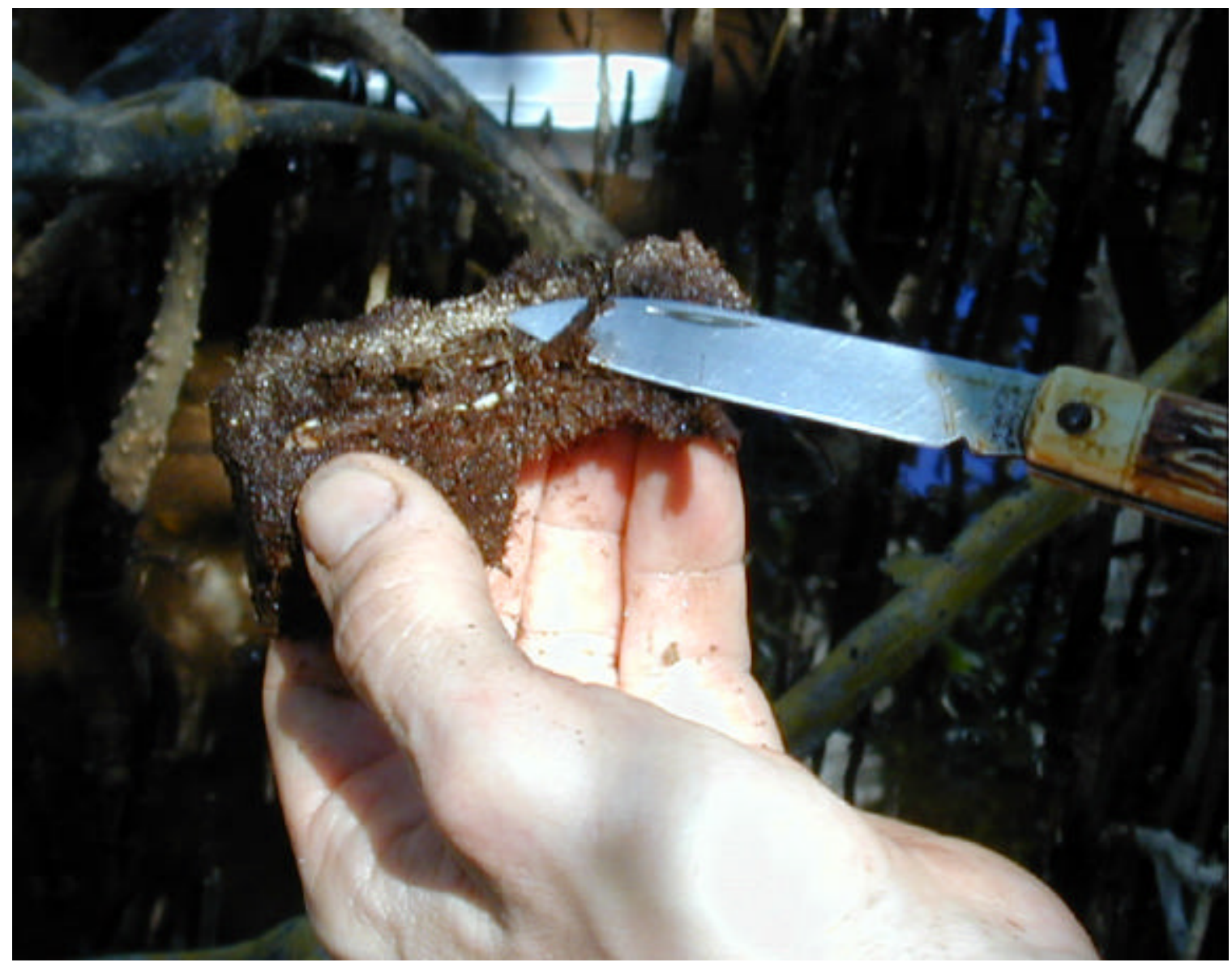


Figure 9. Map of Punta de Manabique, along the Gulf of Honduras coast of Guatemala, showing the location of the mangrove forests where sediment surface responses to both high and low hurricane wave-induced impacts were studied. The exposed side of the peninsula (circled in red) suffered high damage from Hurricane Mitch. The protected inland side was unscathed (circled in purple).

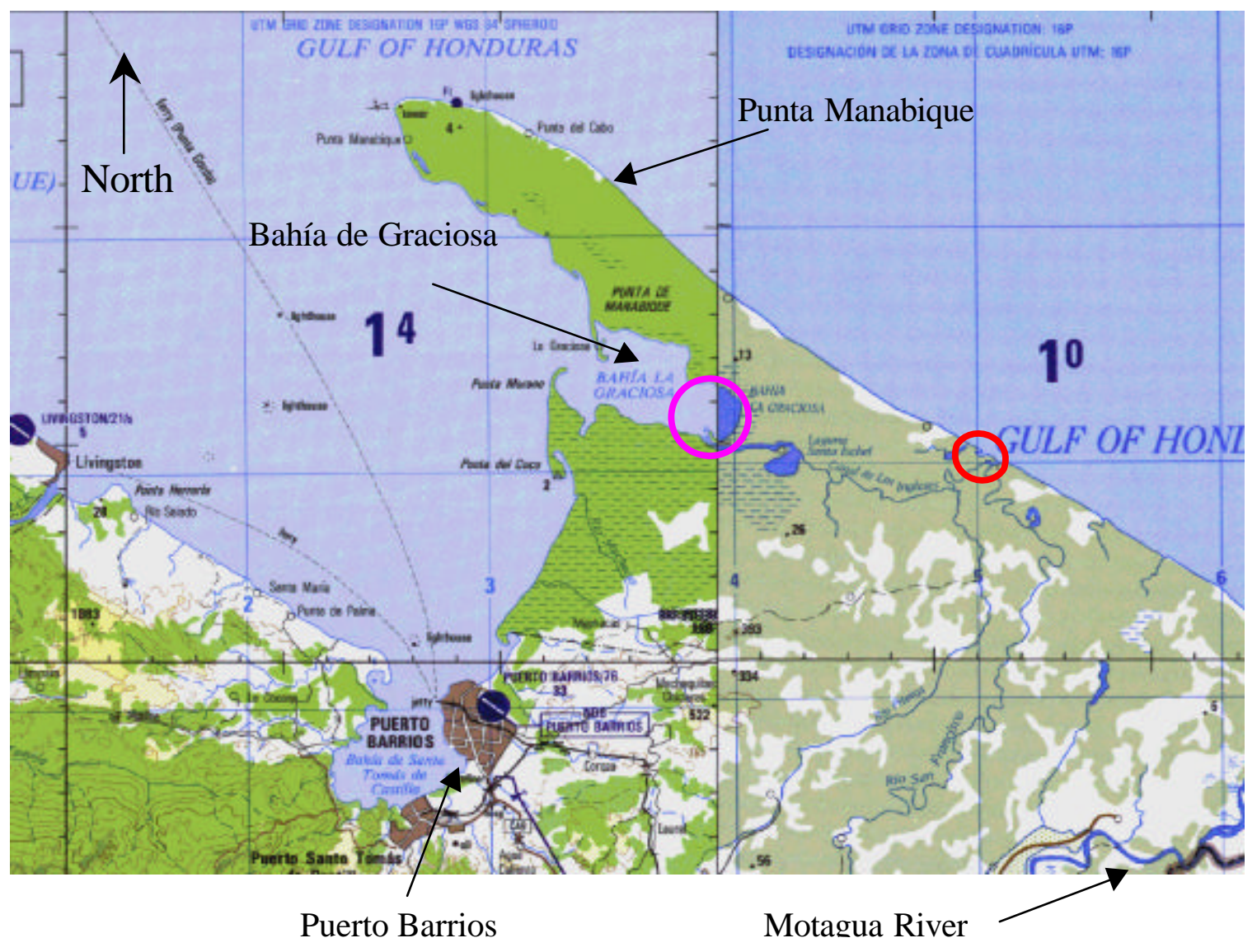


Figure 10: Mangrove shoreline forests in Punta de Manabique, Guatemala, which were studied for Hurricane Mitch-related impacts: A) Low impact shoreline (Bahía de Graciosa); and B) High impact shoreline (Punta de Manabique, near Jaloa).

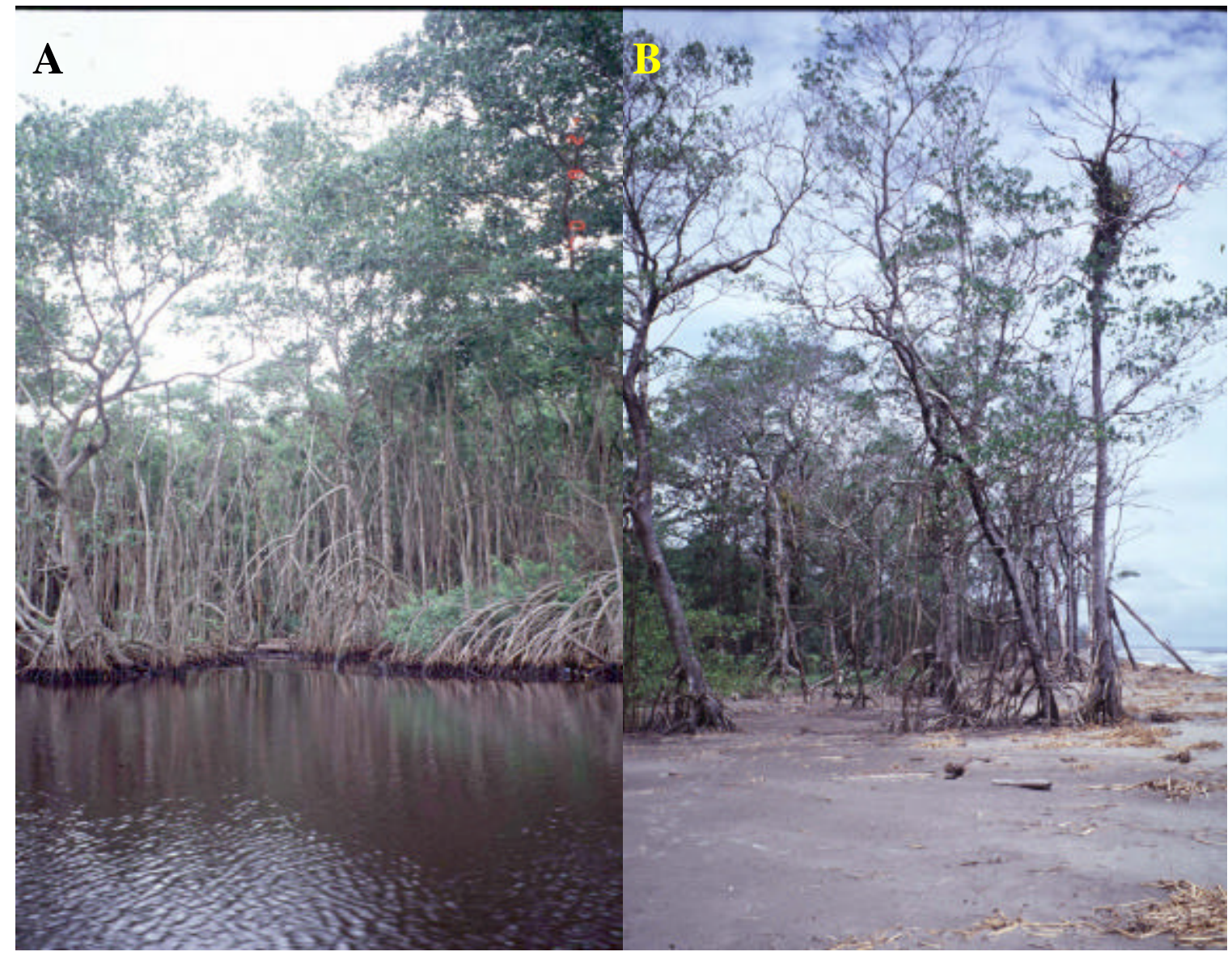


the northern shore of the bay, and one plot was established along the southern shore (fig. 10). Due to the paucity of remaining highly impacted mangrove forests along the north shore of Manabique, all three replicate plots were chosen in the vicinity of the Jaloa settlement (in an area locally called "Remolinos"; fig. 10). As in the Bay Islands, one Rod SET station and three replicate marker horizons were established within each plot. Sand markers were placed at the same time that baseline readings of the Rod SET were taken (August 2000). Because the high impact area was covered in hurricane-deposited sand, no markers were placed here at this time. Successive readings of the Rod SET and markers occurred in January and August 2001. In January 2001, plastic perforated PVC plates were inserted into the sand at the high impact plots to serve as accretion markers. Initial depths to the plates were read in January, with one subsequent reading taken in August 2001. The experimental design was therefore a repeated measures, one-factor model (CRD for impact levels) with nested error structure (pins, positions/horizons and plots).

According to local inhabitants, upland runoff from Hurricane Mitch delivered sediments to the Gulf of Fonseca at several locations, and these sediments were subsequently widely distributed around the gulf. The mangrove forests most severely affected by sediment burial and debris flows were located in the upper reaches of the Conchalitos estuary, near San José de las Conchas $\left(13^{\circ} 20^{\prime} \mathrm{N}, 87^{\circ} 24^{\prime} \mathrm{W}\right.$; fig. 11). It is here that the avulsion of the Choluteca River emptied into the estuarine reaches of the Gulf of Fonseca as a result of Hurricane Mitch (Hensel and Proffitt, 2002). Mangrove forests were chosen in this area to represent high and medium sedimentation impacts. Triplicate random plots were 
Figure 11. Map of the central region of the Gulf of Fonseca (Honduras), where the study of Hurricane Mitch-induced sediment impacts to mangrove forests was conducted. High and medium-impact sites circled in red; low impact sites circled in purple. The path of the Choluteca River during the hurricane is indicated by the red arrow.

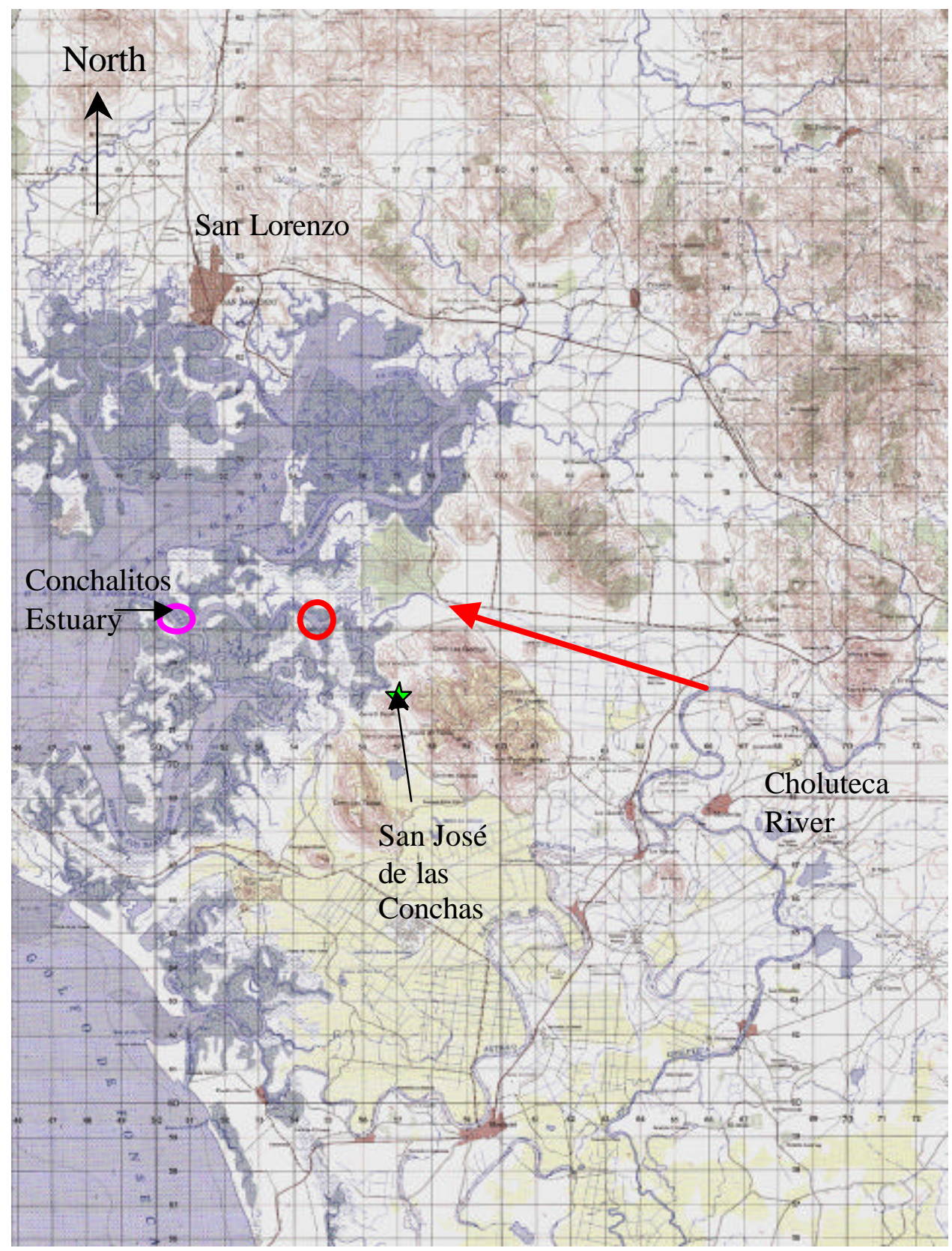


Figure 12. Mangrove shoreline and dwarf interior forests in the Gulf of Fonseca (Honduras) where Hurricane Mitch-related impacts were studied: A) Low impact shoreline (near mouth of Conchalitos estuary); B) Low impact (dwarf) interior forest; C) Medium impact shoreline (near San José de las Conchas); D) Medium impact (dwarf) interior; E) High impact shoreline (near San José de las Conchas); F) High impact interior (an abandoned shrimp pond).

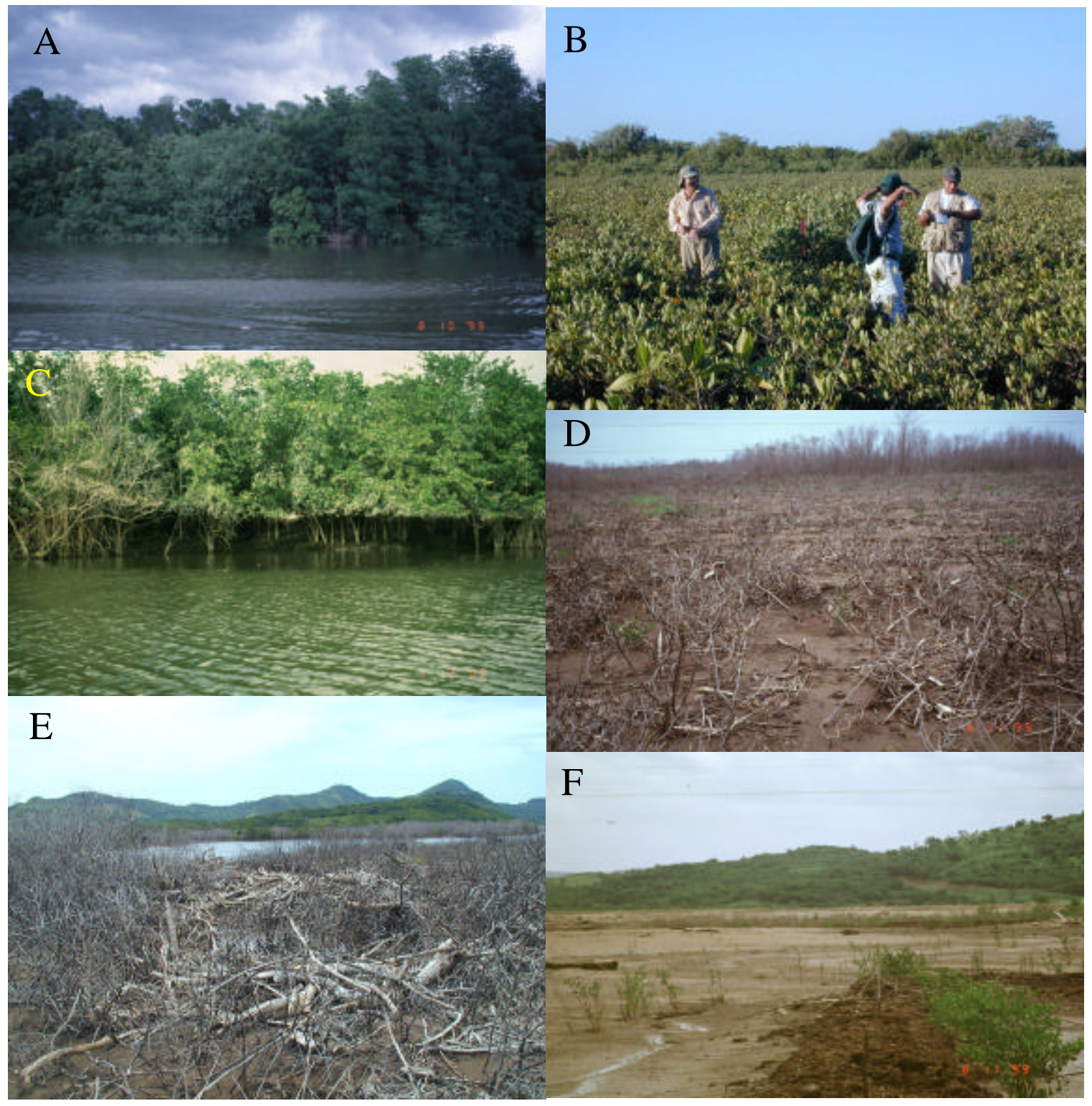


chosen in both shoreline and interior mangrove forests at these impact levels (fig. 12). The high impact interior plots, however, were located in an abandoned shrimp pond whose surface had been graded by the landowner sometime between August 1999 and January 2000. Therefore, these plots represent not only Hurricane Mitch impacts, but also some degree of human impacts that can be considered steps towards the restoration of prehurricane sediment elevations. Mangrove forests that received little or no Hurricane Mitch impacts were identified near the mouth of the Conchalitos estuary $\left(13^{\circ} 20^{\prime} \mathrm{N}, 87^{\circ} 27^{\prime} \mathrm{W}\right.$; fig. 11$)$. Triplicate shoreline and interior mangrove forest plots were chosen at random within this area. A total of 18 plots were therefore included in this part of the study.

One Rod SET station and three marker horizons were established in each plot in the Gulf of Fonseca in late April 2000. Subsequent readings of the Rod SET and markers were made in August 2000 and January, April, and August 2001. In the Gulf of Fonseca, the intertidal zones were not similar across impact levels due to two considerations. First, the high impact interior represented a mixture of different impact mechanisms: dwarf mangrove interior forest converted into a shrimp pond, then buried, graded, abandoned, then restored to a shrimp pond. Second, low impact sites were located downstream, which represented a somewhat different habitat type and made direct comparisons tenuous. The design was therefore considered as a one-factor model (CRD), repeated over time. The factor was present at six levels, representing the different impact and zone combinations, and had nested error. 


\section{Relative Elevation Model}

Measurements of vertical accretion and shallow subsidence do not necessarily integrate long-term processes that affect wetland elevation and sediment collapse, such as compaction and decomposition. Additionally it may take several years before a clear trend emerges from these types of data. Finally, these types of measurements do not take into account possible elevation feedback mechanisms on the processes themselves. For example, a change in elevation typically alters flooding patterns that can in turn affect rates of sediment deposition, decomposition, and autogenic primary production. For these reasons, site-specific computer models that consider all of the relevant processes over appropriate time scales and incorporate feedback mechanisms can provide an additional and complimentary tool for examining the response of wetland elevation to various perturbations (Callaway and others, 1996; Rybczyk and others, 1998; Day and others, 1999). The field measurements of vertical accretion and elevation change described above not only give some indication of short-term wetland elevation dynamics but also provide data for model initialization and calibration. We used the field elevation and accretion data collected as part of this study to modify, initialize, and calibrate a previously published wetland elevation model (Rybczyk and others, 1998; Day and others, 1999). We applied the sediment elevation model to the high impact basin forest on Guanaja because this forest suffered complete tree mortality, was undergoing a rapid loss of elevation, and exhibited little potential for natural forest regeneration (i.e., there was no propagule colonization and no adjacent live forest to serve as a source of propagules). The model was calibrated by comparing observed percent organic matter 
over depth (McKee and McGinnis, 2002) with the simulated output of the same parameter.

Determining Field Elevations. It was necessary to obtain site elevation data for the simulation model because mineral inputs, primary production, and rates of decomposition are all functions of sediment elevation. Using standard techniques (profile leveling with a theodolite and survey rod), we measured the elevation of the Bay Island Rod SET sites relative to mean low low water (MLLW) on August 22 through August 24, 2001.

Model Development. The model used here is similar in framework to the mechanistic wetland soil genesis model developed by Morris and Bowden (1986) and Rybczyk and others (1998) to simulate elevation changes in forested wetlands. It incorporates a mineral sediment deposition function that is derivative of the algorithms developed by Allen (1990) and French (1993), and primary productivity algorithms developed by Chen and Twilley (1999) that are specific to mangrove wetlands. A complete description of the generic model including validation exercises is provided in Rybczyk and others (1998). A brief description of the model and modifications to the published model are provided in Appendix A.

\section{Statistical Analyses}

Sediment elevation (Rod SET) data and vertical accretion (marker horizon) data were analyzed separately, although identical models were used. Rod SET data were calculated as cumulative change for each pin from the baseline reading. Average cumulative change 
was then calculated over the nine pins, then over the five positions within each Rod SET station. Marker horizon data were averaged per core, then per horizon and per plot. A Durbin-Watson test was performed on each data set to test for significant first-order serial correlation. Since all tests were nonsignificant, the data were analyzed using an analysis of covariance (ANCOVA), with time as the covariate (SAS Proc Reg: SAS, 2000). The data sets included zeros corresponding to the baseline readings or initial deployment of the marker horizons, and the models were run forcing the intercept through the origin. Different slopes therefore corresponded to the six different impact by zone treatment combinations (or impact levels, in the case of Punta de Manabique). A stepwise regression procedure was invoked to select for the most efficient model, which essentially compared the six different treatment combinations (two treatment combinations for Manabique).

\section{Results}

\section{Bay Islands, Honduras}

Vertical accretion rates $18-33$ months after the storm were uniformly low $\left(0.2 \mathrm{~cm} \mathrm{yr}^{-1}\right)$ in all forest plots except those in the high impact shoreline forest on Guanaja, where the accretion rate was $1.4 \mathrm{~cm} \mathrm{yr}^{-1}$ (figs. 13 and 14). This high accretion rate is related to the accumulation of encrusting algae in the dead shoreline forest rather than inorganic sediment deposition (fig. 15). In the dead interior mangrove forest on Guanaja, the source of accreted material is likely sediments reworked from within the degraded substrate. Two notable accretionary events were recorded in both the high and medium impact shorelines; one occurred between August 2000 and January 2001 and another 
Figure 13. Cumulative vertical accretion above sand marker horizons in the shoreline mangrove forests of the Bay Islands (Honduras), over the period May 2000 August 2001. Means and slopes calculated from an analysis of covariance.

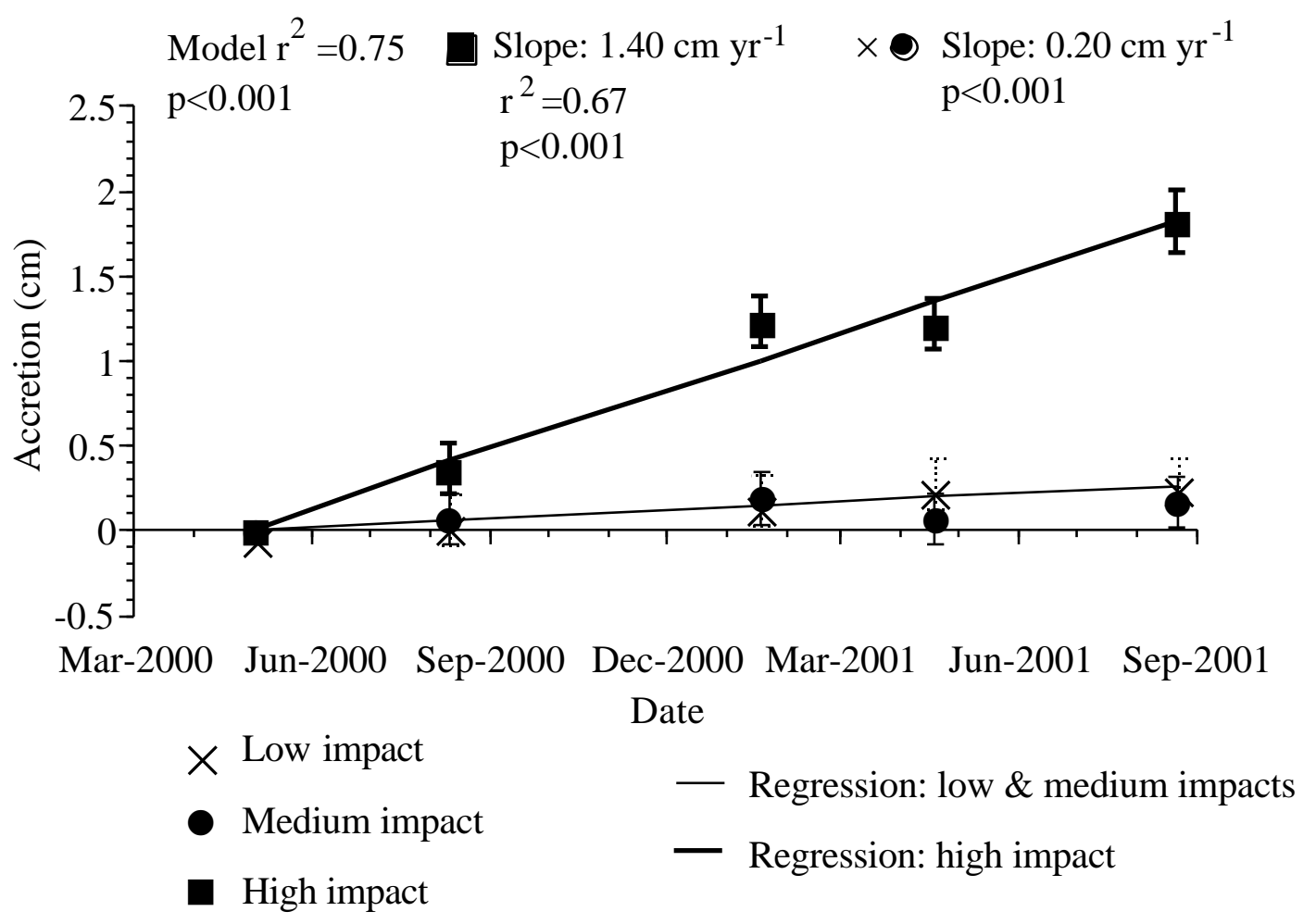


Figure 14. Cumulative vertical accretion above sand marker horizons in the interior mangrove forests of the Bay Islands (Honduras), over the period May 2000August 2001. Means and slopes calculated from an analysis of covariance.

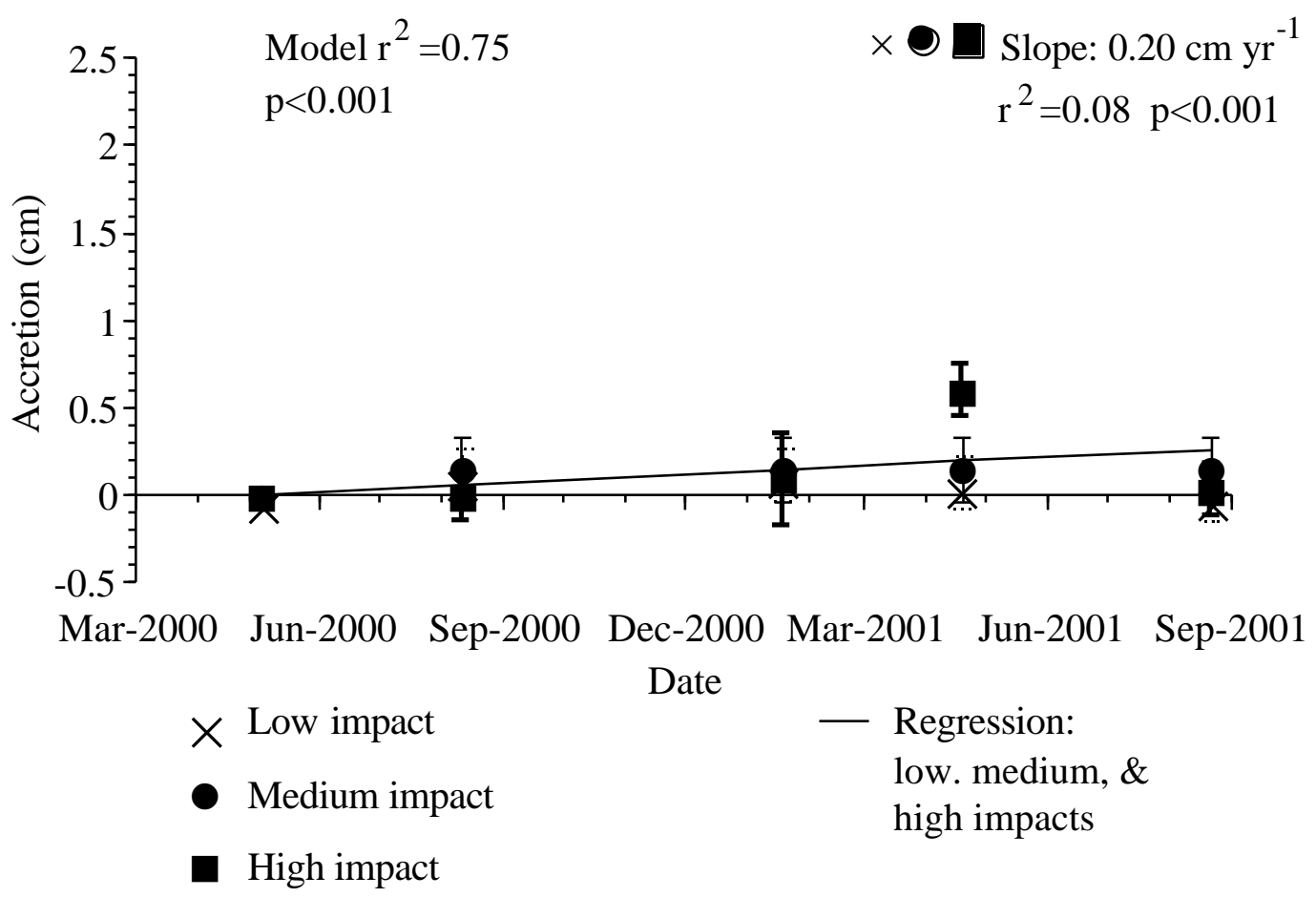


Figure 15. Vertical accretion on top of sand marker horizon in a shoreline mangrove forest which sustained high impact from Hurricane Mitch (Mangrove Bight, Guanaja, Honduras). Core sample represents accretion over a 12.5-month period May 2000 - April 2001, and shows the accumulation of encrusting algae and other materials over the marker surface.

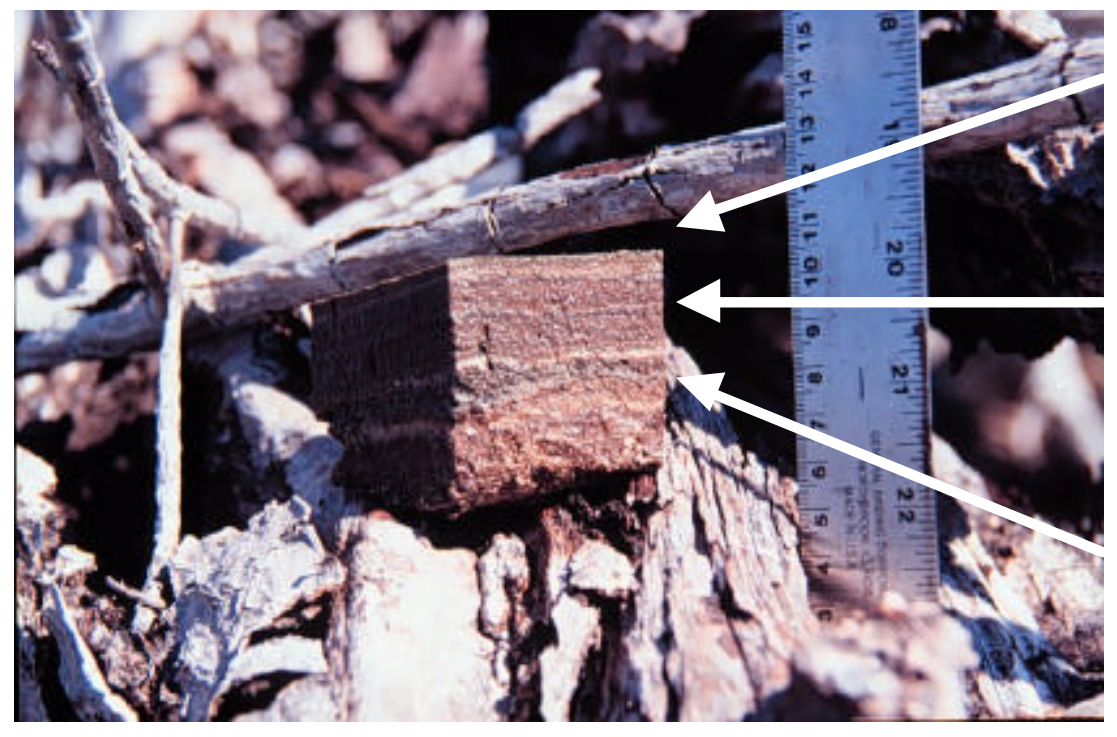

Live algae on sediment surface

Accumulated material in very thin layers

Sand marker horizon 
occurred between April and August 2001 (fig. 13). The absence of this trend within the low impact shoreline and all interior plots (fig. 14), and the fact that both medium and high impact shorelines have an aspect to the North, suggests the deposition was from two (northerly) storm events. There is no evidence that these patterns reflect a chronic Hurricane Mitch-related impact.

Elevation change in the Bay Island mangrove forests showed that vertical accretion was not the only process contributing to sediment elevation dynamics. Despite positive accretion, significant elevation losses were measured in the medium and high impact interior forests (-0.92 and $-0.95 \mathrm{~cm} \mathrm{yr}^{-1}$, respectively; fig. 16). This elevation loss suggests that sediment compaction, or peat collapse, is occurring in these dead and dying mangrove forests. Interestingly, there was a strong seasonal component to the elevation signal for these forests with elevation first declining, then increasing, then declining, and then increasing. No statistical relationships to tide, phase of the moon, or the presence/absence of water on the plots were found. This trend therefore suggests that a seasonally varying belowground process, such as water storage, was influencing elevation in addition to the processes of oxidation and compaction that are driving the peat collapse.

Sediment compaction also played an important role in the high impact shoreline forest where elevation change was positive. During the first 12 months of measurements, elevation change matched accretion very closely, demonstrating the importance of algal mat development in controlling sediment elevation (figs. 13 and 17). However, during 
Figure 16. Cumulative surface elevation change in the interior mangrove forests of the Bay Islands (Honduras), over the period May 2000 - August 2001. Means and slopes calculated from an analysis of covariance.

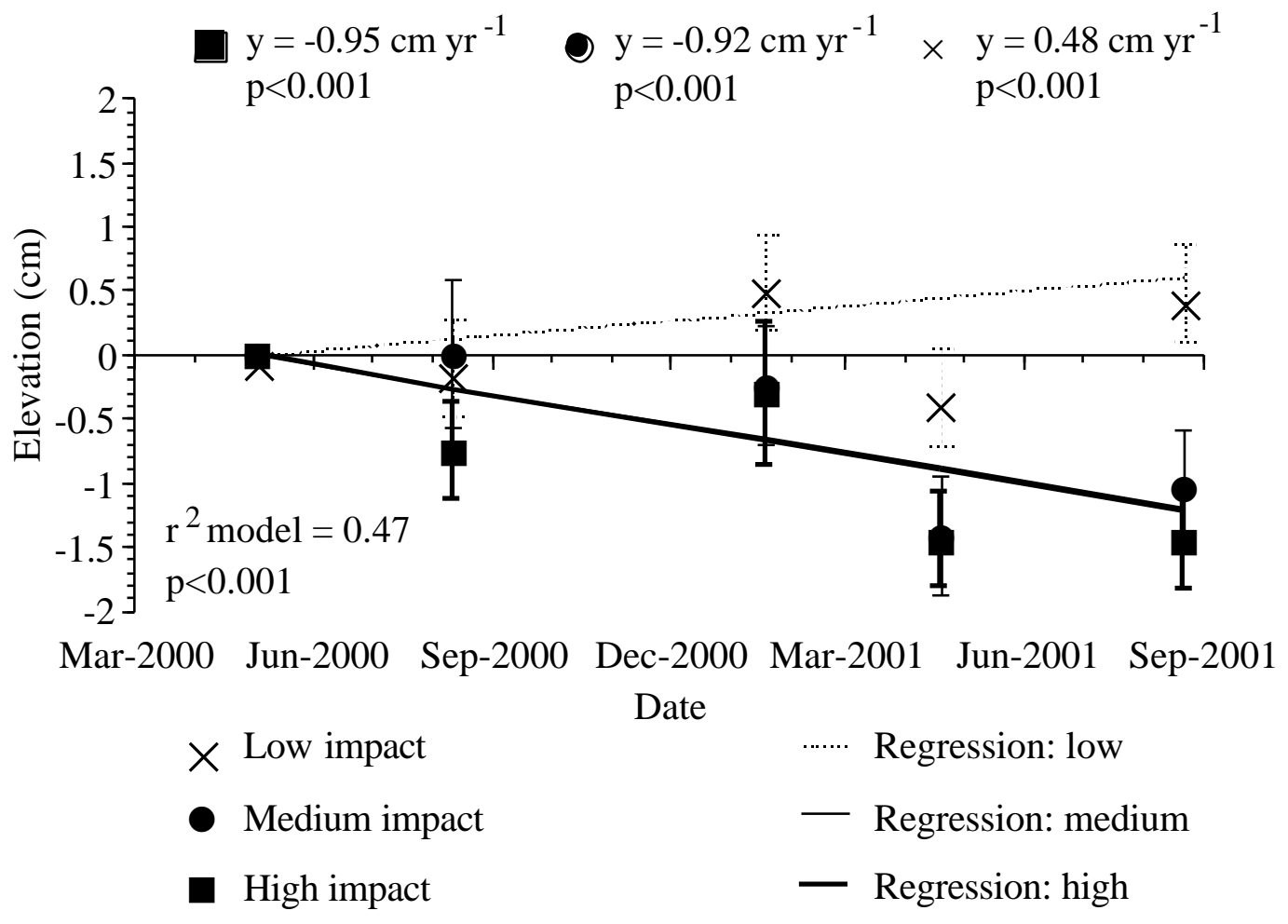


Figure 17. Cumulative surface elevation change in the shoreline mangrove forests of the Bay Islands (Honduras), over the period May 2000 - August 2001. Means and slopes calculated from an analysis of covariance.

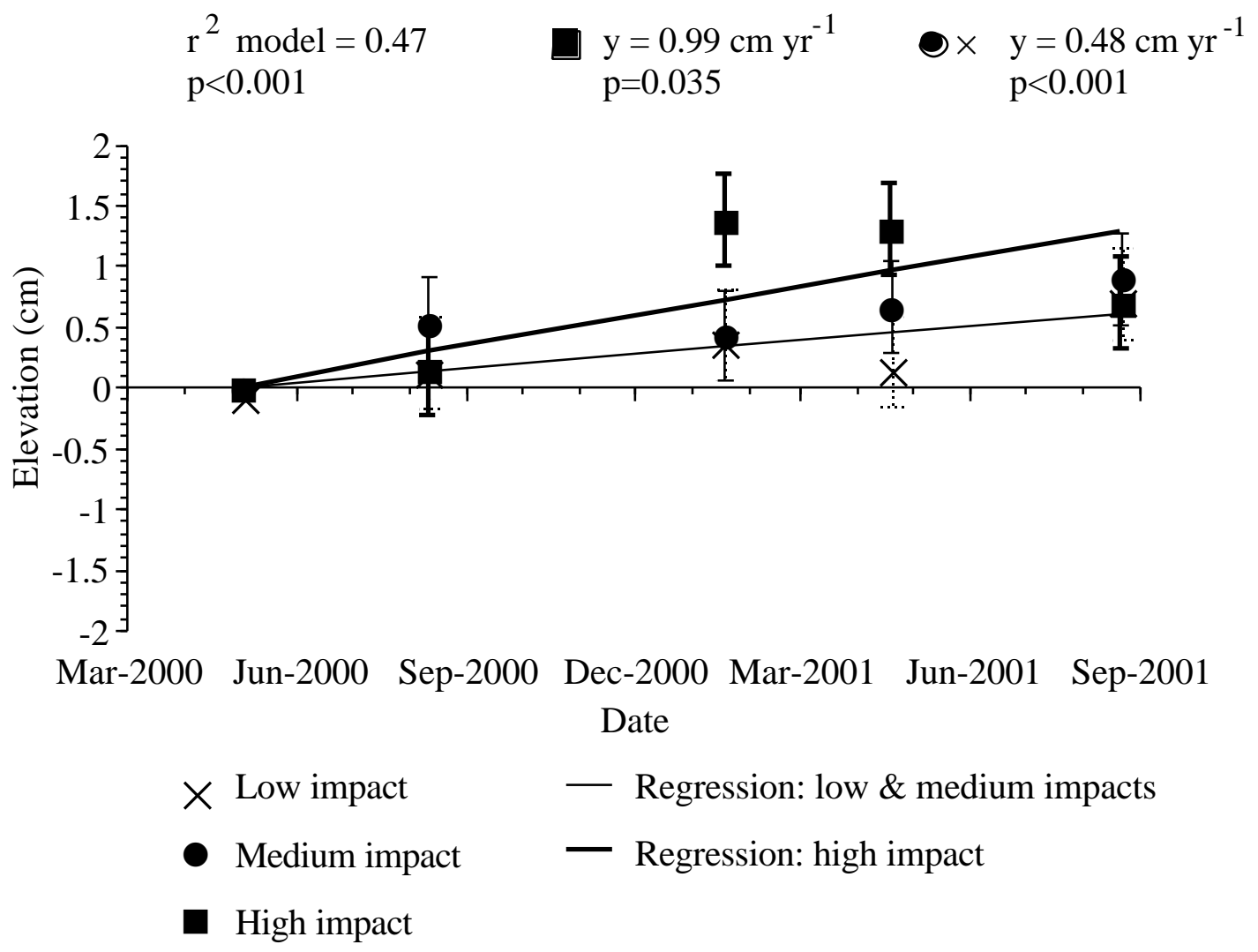


the last sampling interval, elevation declined substantially while accretion increased substantially, such that the annual rate of elevation change $\left(0.99 \mathrm{~cm} \mathrm{yr}^{-1}\right)$ lagged behind vertical accretion $\left(1.4 \mathrm{~cm} \mathrm{yr}^{-1}\right)$. The decrease in elevation in the dead shoreline forest suggests that this substrate is beginning to undergo peat collapse similar to the dead interior forest. The red mangrove (Rhizophora mangle L.) that dominates the shoreline forest produces a denser, more extensive, and stronger peat than the black mangrove (Avicennia germinans (L.) Stearn), which is predominant in the mixed-species interior forest (McKee and McGinnis, 2002). Such a difference between mangrove species likely explains why peat collapse is occurring more slowly in the shoreline forest than in the interior forest. The importance of subsurface processes in controlling sediment elevation is also indicated in the finding that the rate of elevation gain in the low and medium shorelines, and the low impact interior was over twice the rate of vertical accretion (figs. 13, 14, 16 and 17). Although high variability exists in the data, this disparity between accretion and elevation suggests belowground processes such as root growth contributed to sediment surface elevation in those forests where tree mortality was minimal.

Guanaja Sediment Elevation Model. Field elevation survey - Tides around the Bay Islands exhibit an asymmetrical diurnal pattern, and local tide charts report water levels relative to MLLW. Not all sites were directly linked to each other during the survey. Tables 2-5 separate the SET sites into groups that were directly linked during the survey. For example, in table 2, SET sites shoreline 1 and interior 1 were directly linked via sighting and backsighting along a traverse. Thus, within each table, the elevation of each site relative to the other sites in the table is reasonably certain. Due to the large distance 
Table 2. Elevation of mangrove forest soil surfaces at low impact site 1 (South Shore Santa Helena mangroves, Roatan, Honduras). All units are in centimeters. Sites were surveyed on August 22, 2001.

\begin{tabular}{lccc}
\hline & $\begin{array}{l}\text { Elevation relative to } \\
\text { other stations } \\
\text { in This Table } \\
(\underline{\text { lowest site }=0 \mathrm{~cm})}\end{array}$ & $\begin{array}{c}\text { Elevation relative } \\
\text { to MLLW }\end{array}$ & $\begin{array}{c}\text { Elevation relative } \\
\text { to Mean Sea Level }\end{array}$ \\
$\underline{\text { Station }}$ & $0.0 \mathrm{~cm}$ & +3.6 & -27.35 \\
Shoreline & $11.0 \mathrm{~cm}$ & +14.6 & -16.35 \\
Interior & & & \\
\hline
\end{tabular}

${ }^{1}$ Mean low low water 
Table 3. Elevation of mangrove forest soil surfaces at low impact site 3 (South Shore Santa Elena mangroves, Roatan, Honduras). All units are in centimeters. Sites were surveyed on August 22, 2001.

\begin{tabular}{|c|c|c|c|}
\hline & Elevation relative to & & \\
\hline$\underline{\text { Station }}$ & $\begin{array}{l}\text { other stations } \\
\text { in this table } \\
\text { (lowest site }=0 \mathrm{~cm})\end{array}$ & $\begin{array}{c}\text { Elevation relative } \\
\text { to MLLW }^{1}\end{array}$ & $\begin{array}{l}\text { Elevation relative } \\
\text { to Mean Sea Level }\end{array}$ \\
\hline Shoreline & 0.0 & +6.9 & -24.1 \\
\hline Interior & 9.2 & +16.1 & -14.9 \\
\hline
\end{tabular}

${ }^{1}$ Mean low low water 
Table 4. Elevation of mangrove forest soil surfaces at medium impact sites 2 and 3 (North Shore Santa Elena mangroves, Roatan, Honduras). All units are in centimeters. Sites were surveyed on August 22, 2001.

\begin{tabular}{lccc}
\hline & $\begin{array}{l}\text { Elevation relative to } \\
\text { other stations } \\
\text { in this table }\end{array}$ & $\begin{array}{c}\text { Elevation relative } \\
\text { to MLLW }\end{array}$ & $\begin{array}{c}\text { Elevation relative } \\
\text { to Mean Sea Level }\end{array}$ \\
& $\underline{\underline{\text { Station }}}$ & & \\
Shoreline 2 & 0 & 41.7 & +72.7 \\
Shoreline 3 & 7.1 & 48.3 & +79.3 \\
Interior 3 & 16.2 & 57.9 & +88.9 \\
\hline
\end{tabular}

${ }^{1}$ Mean low low water 
Table 5. Elevation of mangrove forest soil surfaces at the high impact sites (Mangrove Bight, Guanaja, Honduras). All units are in centimeters. Sites were surveyed on August 24, 2001.

\begin{tabular}{|c|c|c|c|}
\hline Station & $\begin{array}{c}\text { Elevation relative to } \\
\text { other stations } \\
\text { in this table } \\
\text { (lowest site }=0 \mathrm{~cm} \text { ) }\end{array}$ & $\begin{array}{c}\text { Elevation relative to } \\
\text { MLLW }^{1}\end{array}$ & $\begin{array}{c}\text { Elevation relative to } \\
\text { Mean Sea Level }\end{array}$ \\
\hline Shoreline 1 & 0 & +24.2 & +47.4 \\
\hline Shoreline 2 & 2.4 & +26.8 & +50.0 \\
\hline Interior 1 & 13.6 & +38.0 & +61.2 \\
\hline Interior 2 & 13.6 & +38.0 & +61.2 \\
\hline Interior 3 & 11.8 & +36.2 & +59.4 \\
\hline
\end{tabular}

${ }^{1}$ Mean low low water 
between sites, it was not possible to directly link the sites within the tables to sites listed in other tables. However, within each table, the sites were also directly linked to the current sea level. Therefore, by noting the time and the current tide level listed on local charts, it was possible to indirectly link all sites (this indirect link is shown as elevation relative to MLLW and mean sea level).

However, it is critical to note that the local tide charts are not specific for the SET sites. Tide data for Roatan were for Port Royal, and tide data for Guanaja were listed simply as "Guanaja." No corrections were given for specific localities. According to the charts, tides ranged from 0 MLLW to $61 \mathrm{~cm}$ above MLLW during the three day span of our survey, and since the tides are semidiurnal, even small time adjustments could dramatically affect the elevation relative to MLLW that we obtained. Additionally, two tropical storms passed through the region during the field campaign, and it is certainly possible that there was some wind-driven setup along the coast.

Due to the problems noted above, we have little confidence in the elevations relative to MLLW and MSL. However, since we know the exact time and location of each survey site, it may be possible in the future to obtain more accurate predictions. This of course would still not solve the problem associated with wind-driven setup. Despite these problems, a clear pattern does emerge when examining elevation differences between shoreline and interior sites. The elevation of the interior sites average $11.6 \mathrm{~cm}$ above the elevation of the shoreline plots with a standard deviation of only $2.3 \mathrm{~cm}$. 
Model Calibration - The model is calibrated by comparing observed sediment characteristics (i.e., percent organic matter, percent mineral matter, pore space, and bulk density, by depth) with the simulated output of the same parameters. Neither of the high impact sites had field measurements of bulk density with depth (only bulk densities near the surface were measured). Percent organic matter was the only sediment characteristic used to calibrate the sediment model since pore space cannot be calculated if bulk density is not known and percent mineral matter is merely a reflection of percent organic matter (percent mineral matter $=100$ - percent organic matter). The simulated sediment columns were in close agreement with observed characteristics at the high impact interior site, although the model did not simulate the very abrupt transition between high and low organic matter found at all sites (fig. 18).

Simulating a Preimpact Forest - We simulated a stable mangrove scenario (fig. 19) for the high impact interior site using both field data and literature values for the various rates and constants required by the model (table1, Appendix). Stable elevations relative to sea-level could only be obtained by using lower published values for relative sea-level rise (RLSR) in the region $\left(0.32 \mathrm{~cm} \mathrm{yr}^{-1}\right)$.

Simulated Hurricane Impacts - Simulations revealed a rapid sediment collapse of 3.7

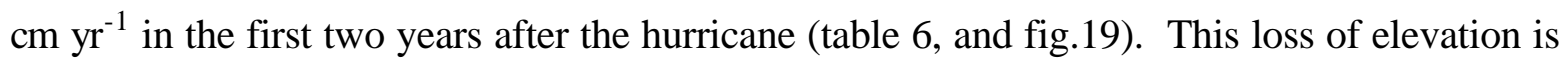
caused by the rapid decomposition of the labile root fraction. Wanless and others (1995) measured a similar rate of elevation loss $\left(2.0-3.0 \mathrm{~cm} \mathrm{yr}^{-1}\right)$ during the 2 years immediately following the death of a mangrove forest in southwest Florida caused by Hurricane Andrew. Two years after Hurricane Mitch, the simulated rate of sediment collapse had decreased to 
Figure 18. Simulated vs. observed sediment organic matter in the high impact mangrove forest on Guanaja (Bay Islands, Honduras).

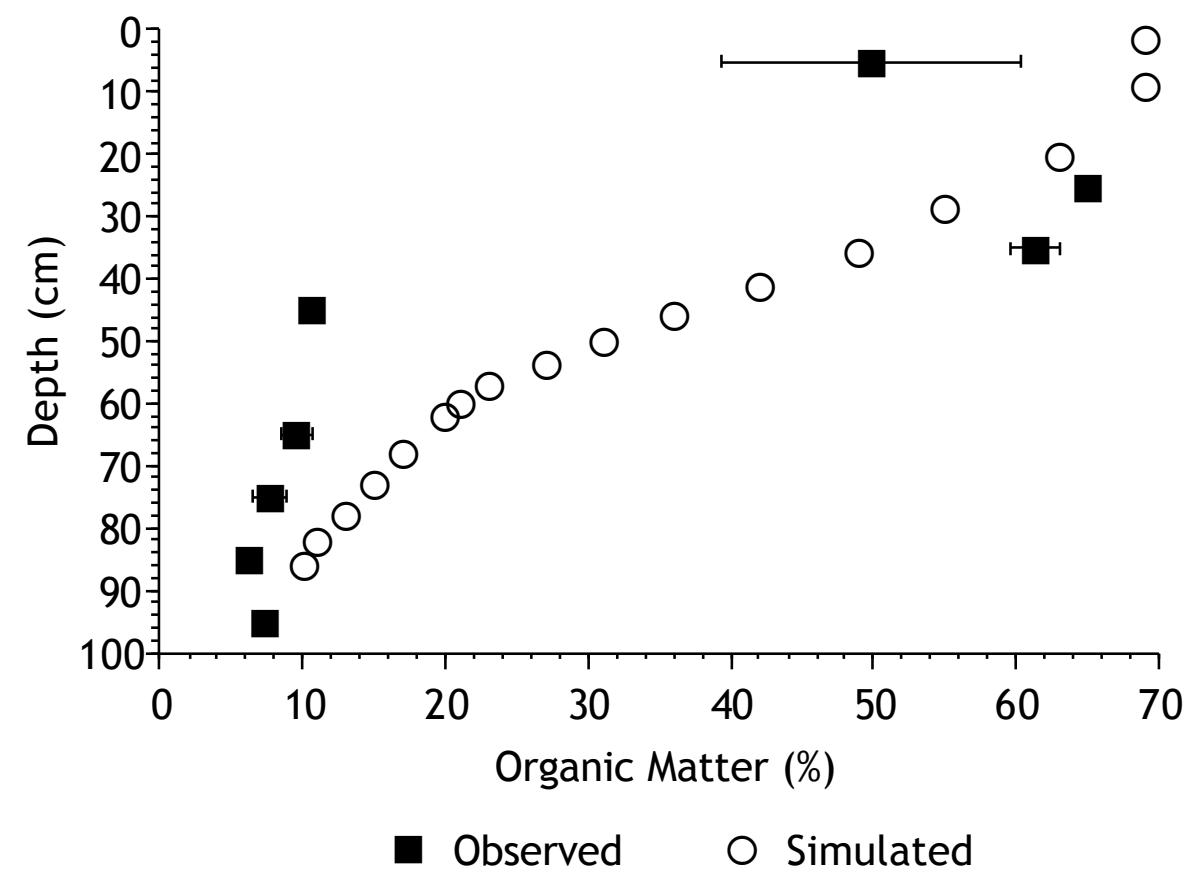


Figure 19. Simulated loss in mangrove forest elevation relative to mean low low water (MLLW) in the high impact mangrove basin for the10 years following Hurricane Mitch ("Hurricane" line) compared to the simulated change in elevation with no hurricane induced mortality ("No Hurricane" line).

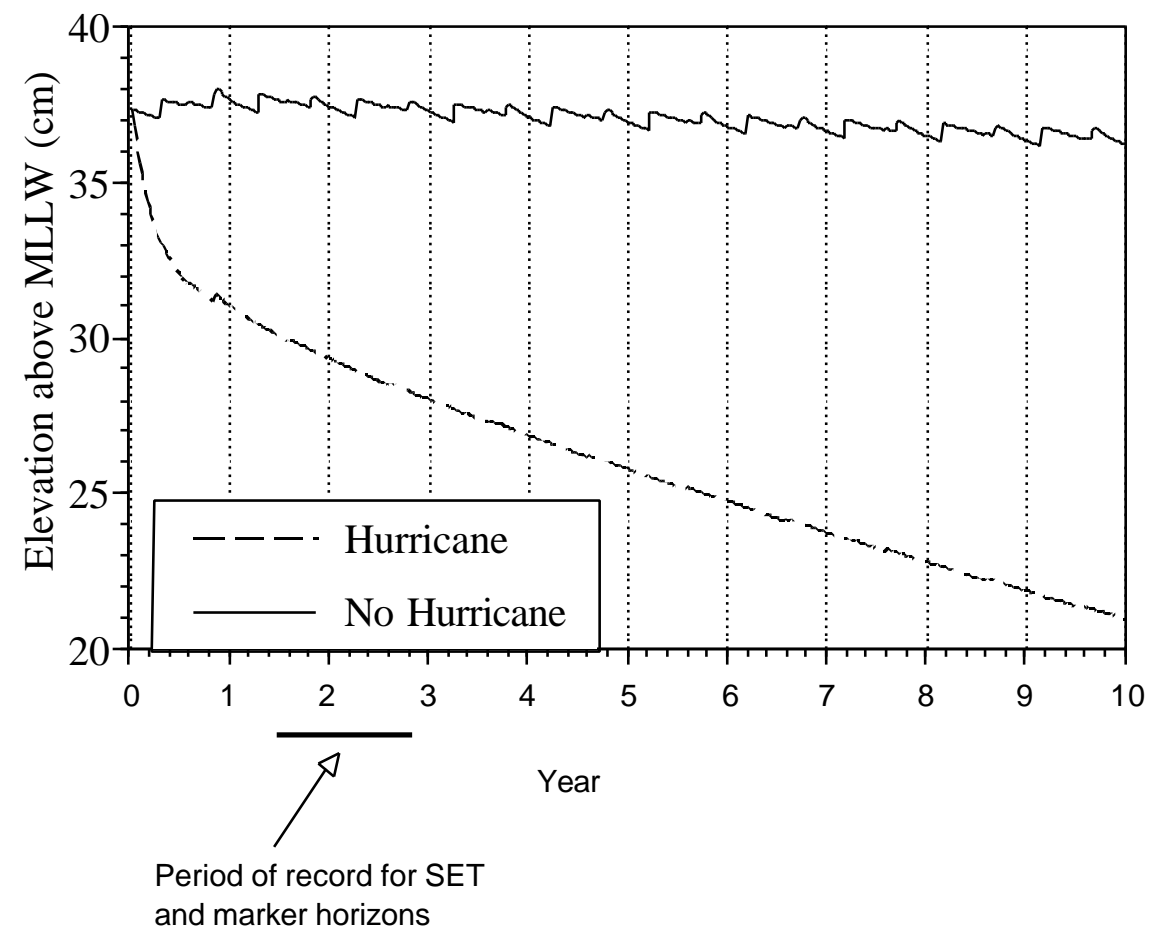


Table 6. Simulated effects of Hurricane Mitch on mangrove forest sediment dynamics and overall wetland elevation at the high impact sites on Guanaja.

\begin{tabular}{|c|c|c|}
\hline & $\underline{\text { Fringe }}$ & Interior \\
\hline Initial elevation relative to MLLW $^{1}$ & $25.3 \mathrm{~cm}$ & $37.5 \mathrm{~cm}$ \\
\hline Elevation relative to MLLW ${ }^{1} 10 \mathrm{yrs}$ after Mitch & $9.22 \mathrm{~cm}$ & $21.0 \mathrm{~cm}$ \\
\hline - loss in elevation relative to MLLW ${ }^{1}$ & $16.1 \mathrm{~cm}$ & 16.5 \\
\hline Loss in elevation due to sediment collapse alone & $12.9 \mathrm{~cm}$ & 13.3.0 \\
\hline Rate of sediment collapse in the first 2 years & $3.5 \mathrm{~cm} \mathrm{yr}^{-1}$ & $3.7 \mathrm{~cm} \mathrm{yr}^{-1}$ \\
\hline Rate of sediment collapse over the next 8 years & $0.72 \mathrm{~cm} \mathrm{yr}^{-1}$ & $0.74 \mathrm{~cm} \mathrm{yr}^{-1}$ \\
\hline
\end{tabular}

${ }^{1}$ Mean low low water 
$0.74 \mathrm{~cm} \mathrm{yr}^{-1}$. Field measurements of sediment collapse did not begin until 18 months after the storm. Thus, we cannot verify the simulated collapse rates during the first two years. However, the rate of sediment collapse measured in the field from 18-33 months after the storm was $1.10 \mathrm{~cm} \mathrm{yr}^{-1}$, similar to the $0.74 \mathrm{~cm} \mathrm{yr}^{-1}$ simulated rate of collapse after two years. The simulated rate of total-relative-elevation loss in the basin forest is higher than the simulated sediment collapse rate (table 6) because simulated elevation loss is a function of both sediment collapse and relative sea-level rise $\left(0.32 \mathrm{~cm} \mathrm{yr}^{-1}\right.$; Emery and Aubrey 1991).

\section{Punta de Manabique, Guatemala}

Twenty-two months after the passage of Hurricane Mitch, no trace of hurricane deposition was seen in the protected bay of Bahía de Graciosa (low impact plots; table 1). Vertical accretion was low $\left(0.036 \mathrm{~cm} \mathrm{yr}^{-1}\right.$; fig. 20), and likely reflects natural processes unaffected by the hurricane. These mangrove sediments are organic (McKee and McGinnis, 2002), and are the product of mangrove forest production. Thus sediment accretion was likely a result of mangrove litter fall and superficial (fine) root growth (fig. 21) with little inorganic sediment input. Net elevation change over the 12-month period was insignificant (fig. 22), which implies that accretion was offset by belowground processes such as shallow subsidence and decomposition, as has been reported for a mangrove forest in Florida, USA (Cahoon and Lynch, 1997).

Storm-related sand deposits measuring between 60 and $120 \mathrm{~cm}$ in depth remained on top of underlying peat in a mangrove forest on the Gulf of Honduras side of Punta de Manabique, Guatemala (high impact plots; table 1). Over seven months (JanuaryAugust 2001), no significant trends in vertical accretion were recorded. Although a 
Figure 20. Cumulative vertical accretion above marker horizons in the shoreline mangrove forests of Punta de Manabique (Guatemala), over the period August 2000August 2001.

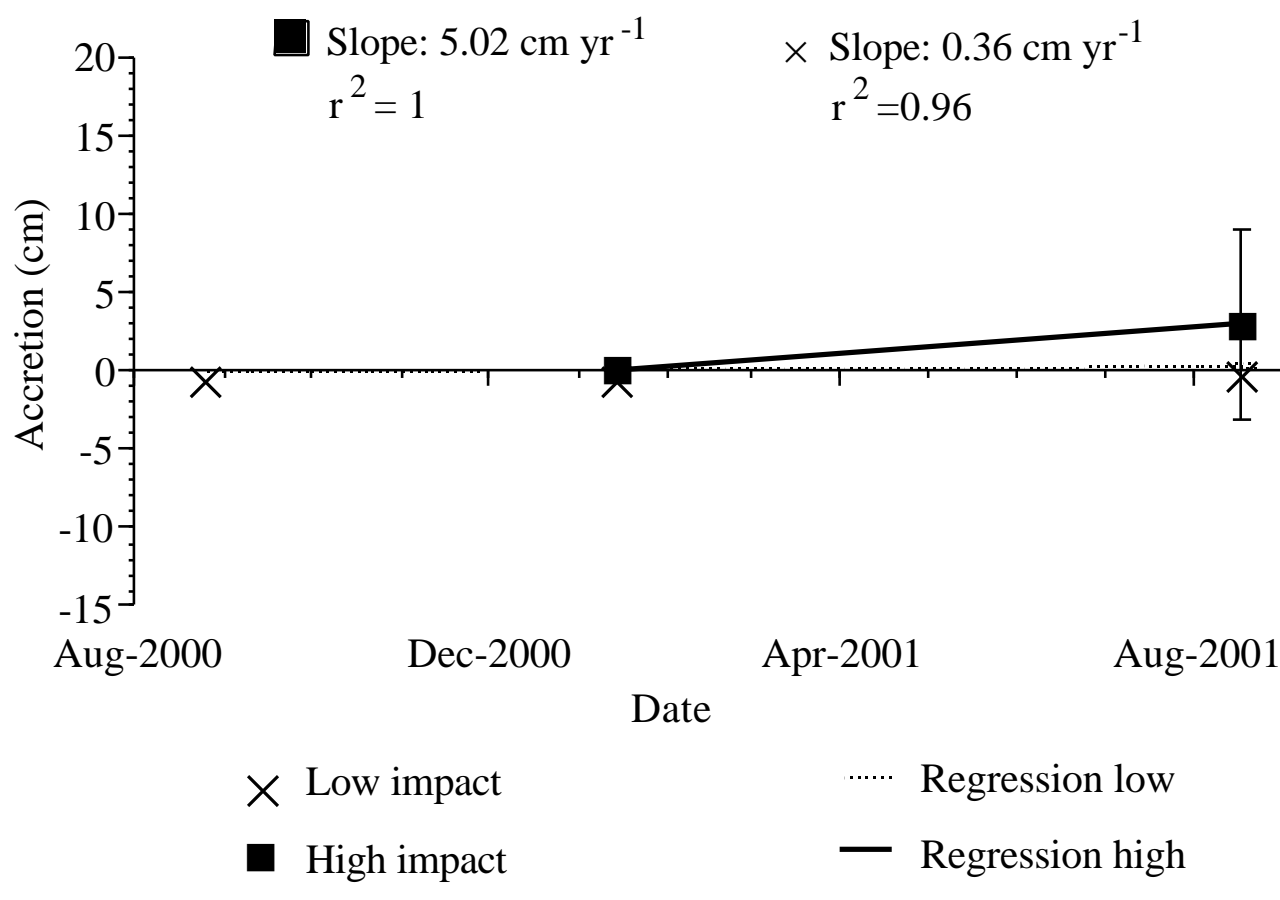


Figure 21. Accumulation of mangrove-derived materials on top of marker horizon plots in a shoreline mangrove forest that sustained low impact from Hurricane Mitch (Bahía la Graciosa, Guatemala). Traces of the sand layer (marker) can be seen, mixed with fine roots and topped with mangrove leaves.

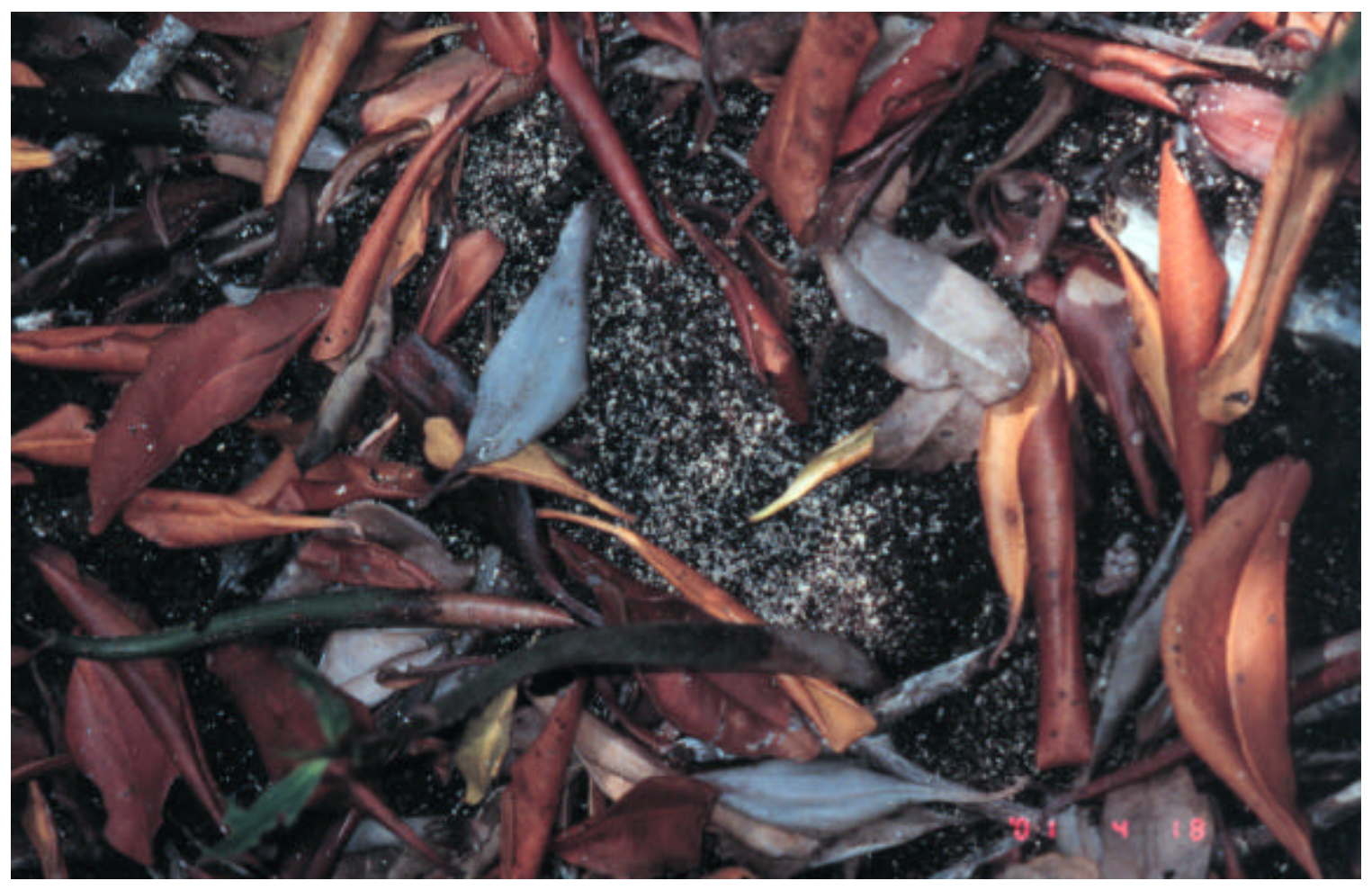


Figure 22. Cumulative surface elevation change in the shoreline mangrove forests of Punta de Manabique (Guatemala), over the period August 2000-August 2001.

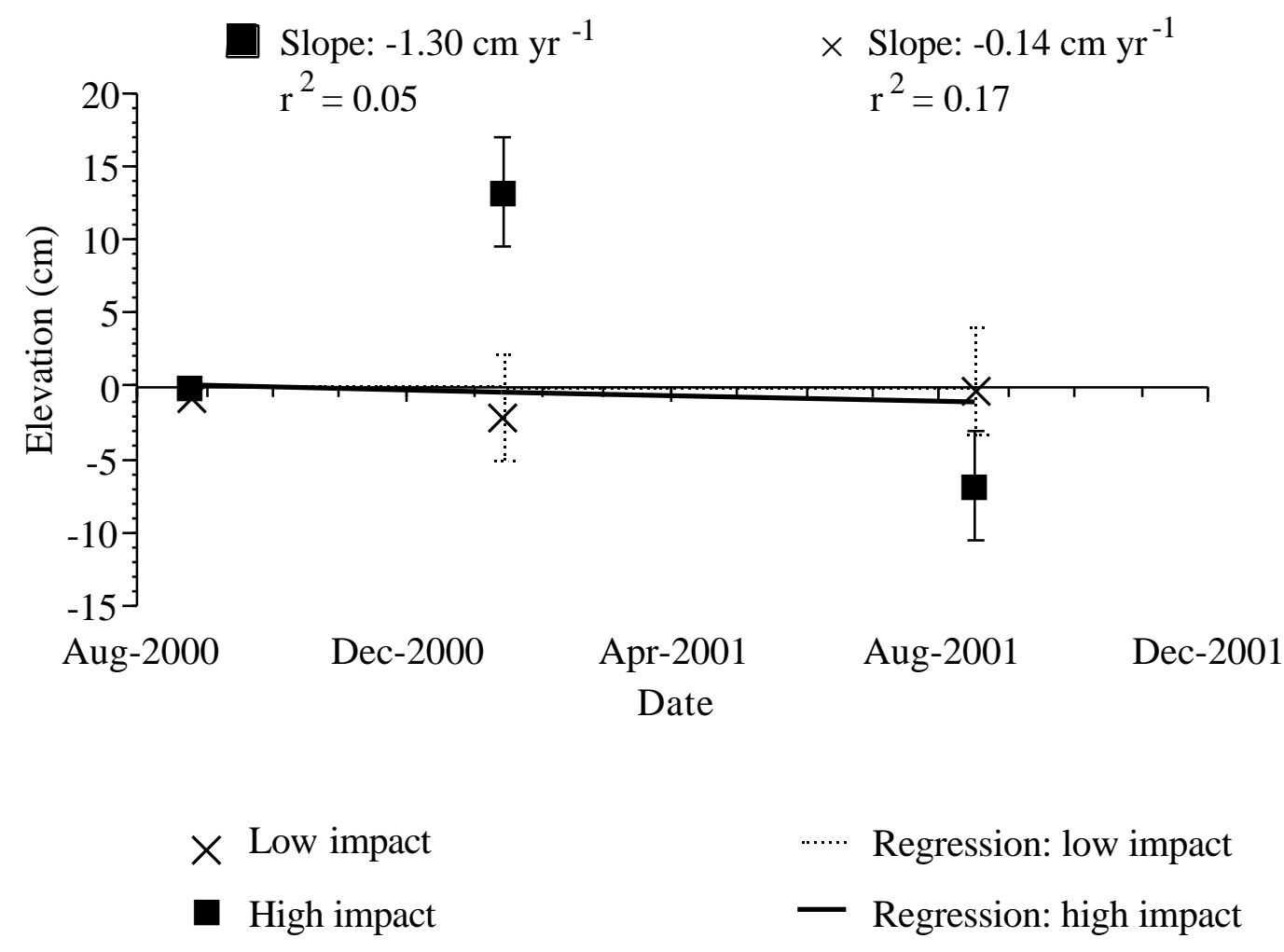


positive trend is suggested in fig. 22 , the accretion data do not reflect the missing marker horizon plates that were eroded away.

Over the 12-month period of study, surface elevation at the high impact plots changed markedly, but there was no significant overall trend revealed by regression analysis (fig. 22). A large increase in elevation was recorded in January 2001, presumably caused by a storm event in November 2000 that mobilized more sand on top of the surfaces previously buried by close to one meter of hurricane-related sediments (Fundación Mario Dary, Puerto Barrios, 2001, oral communication.). The net effect of this accretion was a net elevation gain of $13.2 \mathrm{~cm}$. By August 2001, all of this accretion was eroded away, as indicated by erosion scarps and surface elevation fell below the poststorm baseline level (-6.8 cm; fig. 22). Hence, sediment elevation remains highly dynamic in this setting three years after the storm.

\section{Gulf of Fonseca, Honduras}

Hurricane Mitch deposited on average 16-90 cm of sediment in the mangroves of the upper Gulf of Fonseca (table 1), while reference mangrove forests received no stormrelated sediment deposits. Despite this acute increase in elevation and consequent reduction in flooding frequency, most study plots showed a trend of sustained vertical accretion 18-33 months after the storm, apparently as a result of reworking of the storm deposits, or in the case of the reference forests, natural sedimentation patterns. The medium impact shoreline, with on average $16 \mathrm{~cm}$ of hurricane deposits (table 1), had a significantly higher accretion rate $\left(1.42 \mathrm{~cm} \mathrm{yr}^{-1}\right.$; fig. 23$)$ compared to the other impact $\times$ 
zone combinations $\left(0.29 \mathrm{~cm} \mathrm{yr}^{-1}\right.$; fig. 24). Although elevation profiles of each mangrove zone were not measured, the medium impact shoreline forest was located on a point bar which was clearly at a lower elevation than both the low and high impact shorelines and all of the interior forests (as evidenced from different levels of flooding from the same tides). The high flooding frequency of the point bar helps explain the high sedimentation rate. The low accretion rate in the interior dwarf forests supports the contention that these higher elevation sites were inundated very infrequently with sediment-rich water, particularly the medium impact interior, which had a $90 \mathrm{~cm}$-thick storm deposit. Over the period of study, several higher-elevation areas were eroding away, with the sediments accumulating on adjacent, lower surfaces. The fluctuating depth of the marker horizon (increasing/decreasing/increasing etc) in the medium impact interior forest (fig. 24) is likely a result of such repeated reworking (erosion and deposition) of the storm deposit.

Surface elevation change readings show that vertical accretion is responsible for only part of the sediment surface dynamics in the mangrove forests of the Conchalitos estuary after the storm. The high impact shoreline and high impact interior forests showed elevation loss while all other impact $\times$ zone combinations had a similar rate of elevation gain $(0.46$ $\mathrm{cm} \mathrm{yr}^{-1}$; figs. 25 and 26). The large decrease in elevation measured at the high impact shoreline was caused by both sediment compaction and lateral erosion. Between 18 and 21.5 months after Hurricane Mitch, this area was stable with respect to elevation change (fig. 25). Soon thereafter, between August 2000 and January 2001, a steady loss in elevation was recorded despite no evidence of systematic erosion (elevation changed over the 15 -month period at rate of $-2.08 \mathrm{~cm} \mathrm{yr}^{-1}$; figs. 23 and 25). Elevation loss is likely 
Figure 23. Cumulative vertical accretion above feldspar marker horizons in the shoreline mangrove forests of the Gulf of Fonseca (Honduras), over the period May 2000-August 2001. Means and slopes calculated from an analysis of covariance.

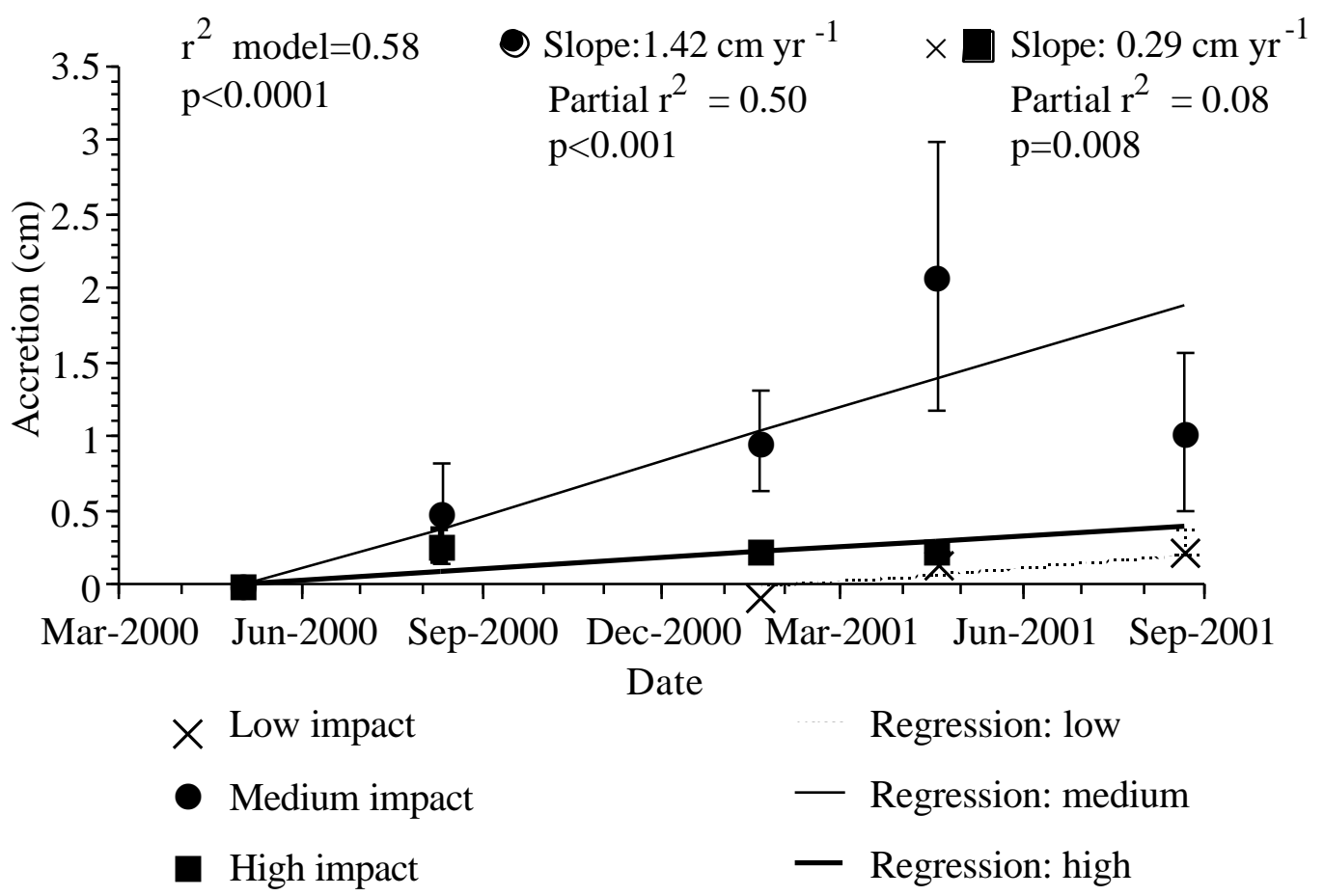


Figure 24. Cumulative vertical accretion above feldspar marker horizons in the interior (dwarf) mangrove forests of the Gulf of Fonseca (Honduras), over the period May 2000 - August 2001. Means and slopes calculated from an analysis of covariance.

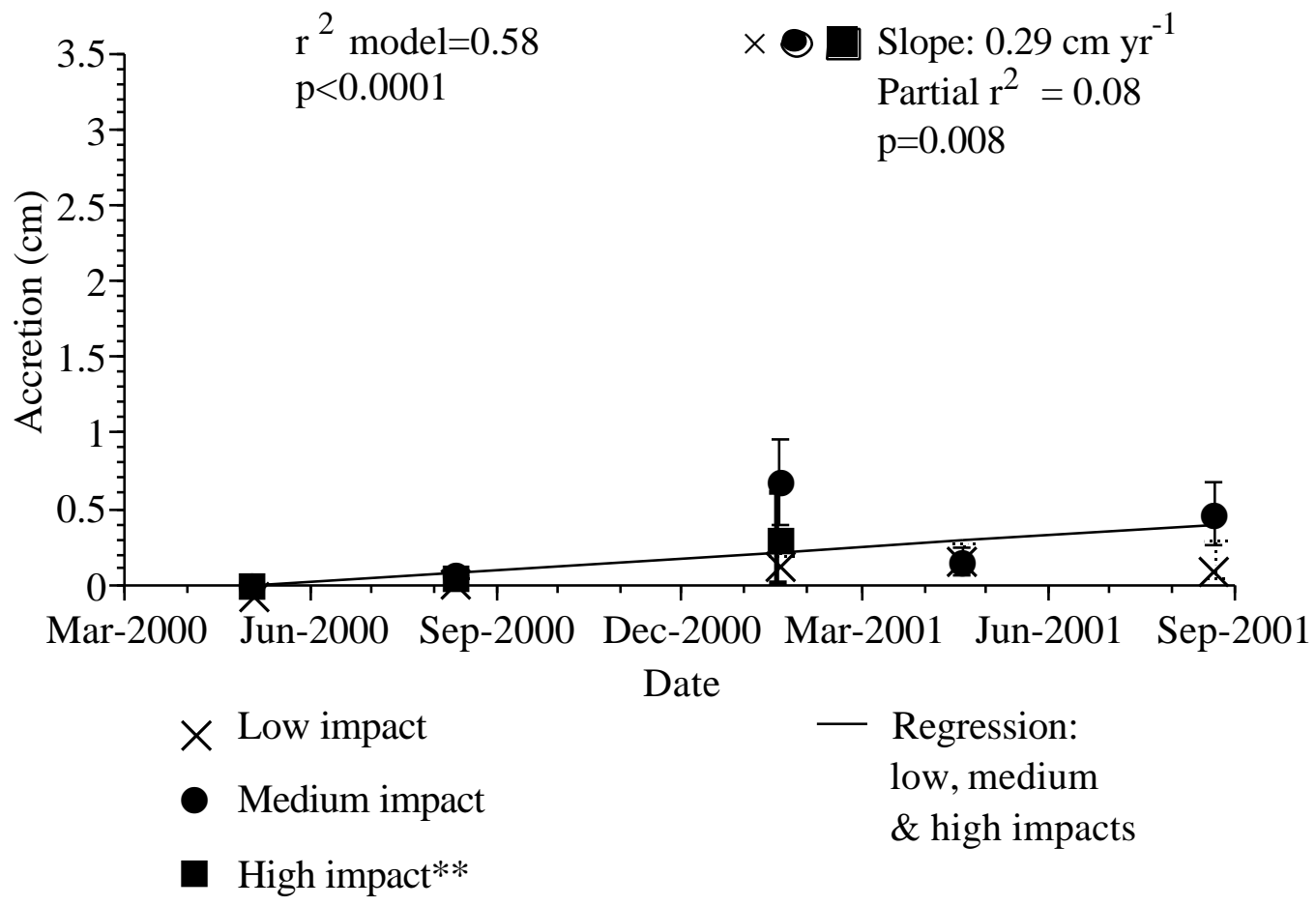


Figure 25. Cumulative surface elevation change in the shoreline mangrove forests of the Gulf of Fonseca (Honduras), over the period May 2000-August 2001. Means and slopes calculated from an analysis of covariance.

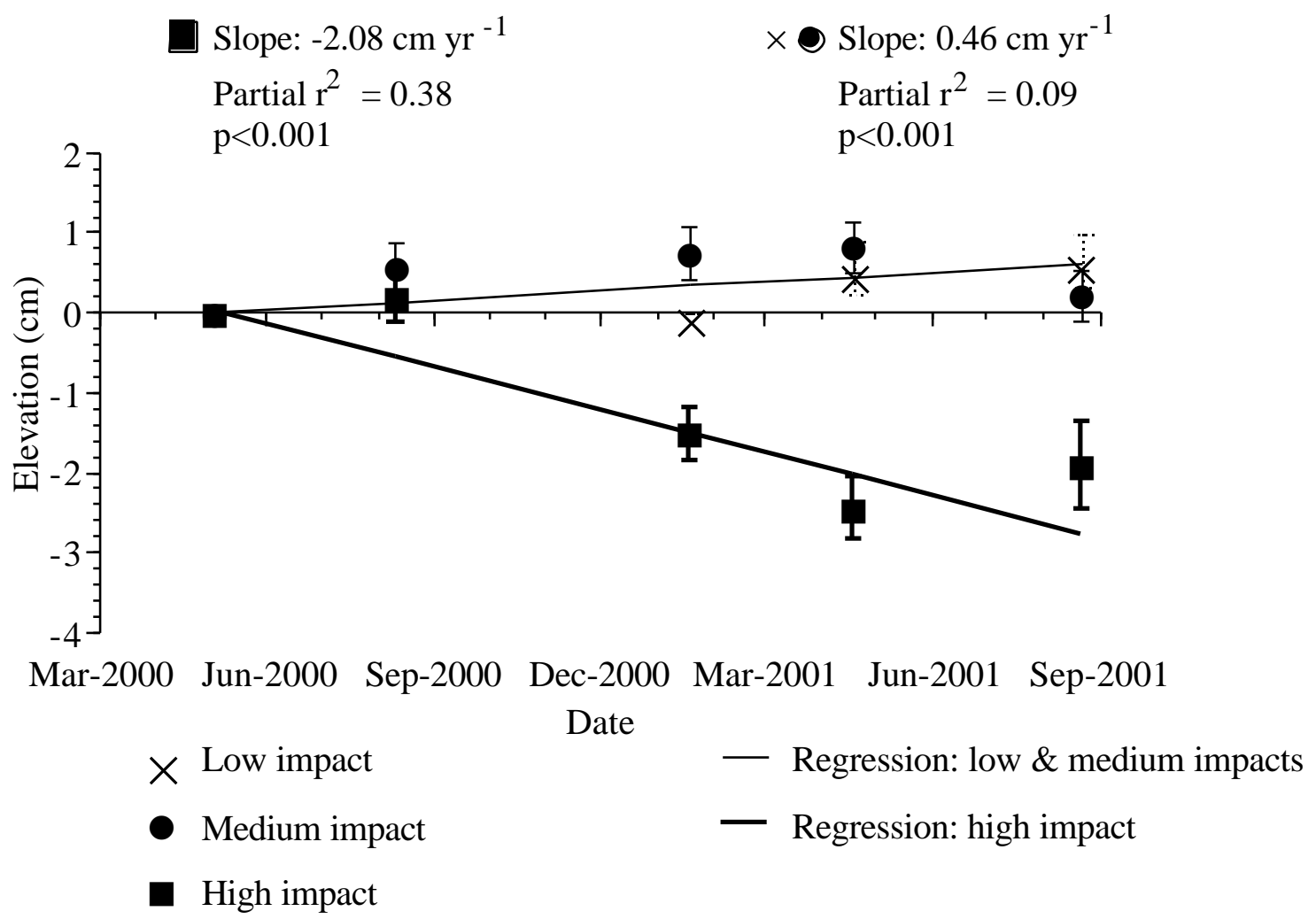


Figure 26. Cumulative surface elevation change in the interior (dwarf) mangrove forests of the Gulf of Fonseca (Honduras), over the period May 2000 - August 2001. Means and slopes calculated from an analysis of covariance.

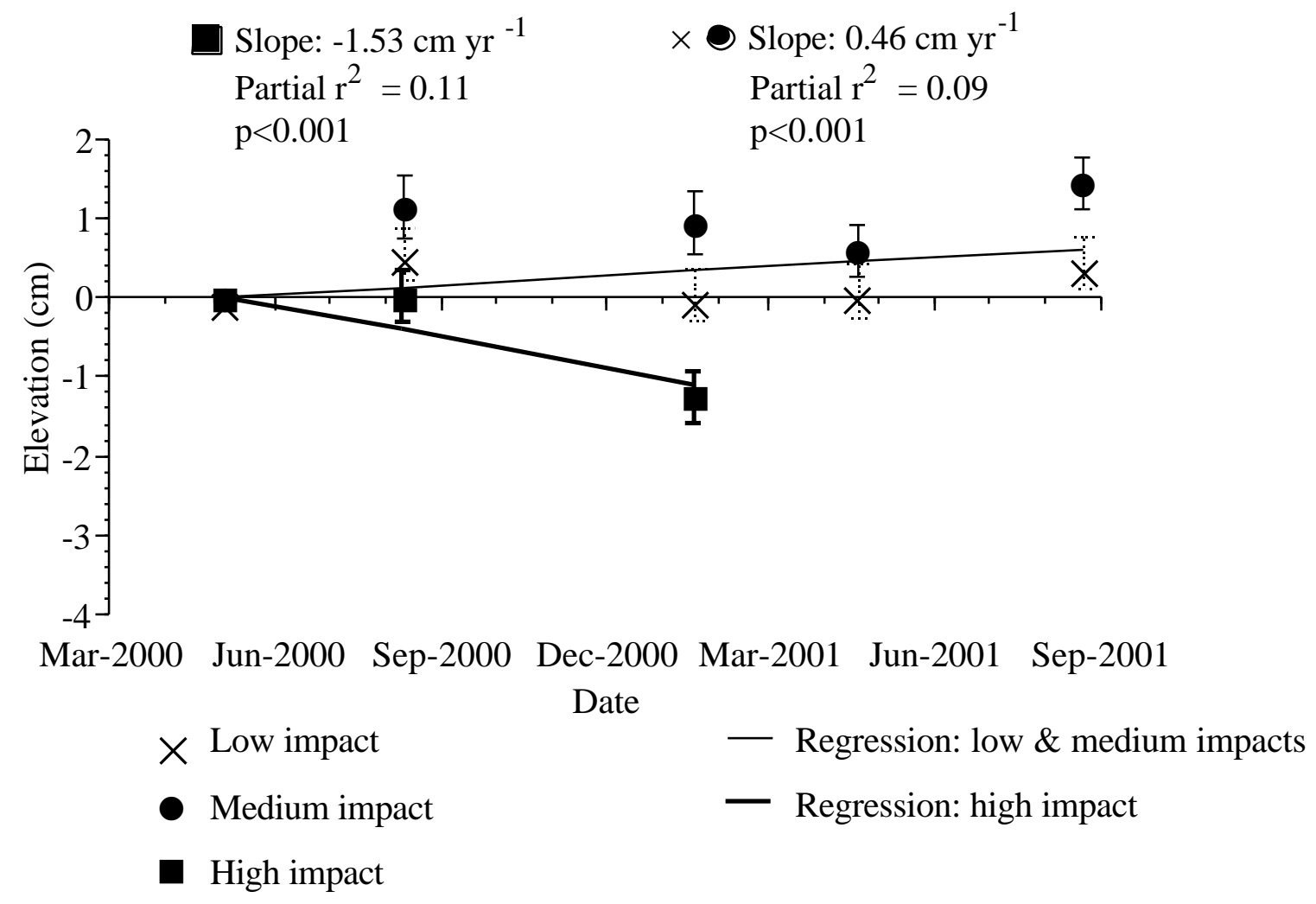


related to compaction and subsidence of either hurricane deposits and/or underlying organic-rich mangrove shoreline sediments. In addition to subsidence, lateral erosion of the shoreline cut bank may have led to slumping of the substrate between January and April 2001, as indicated by erosion scarps ranging from 1.0 to $4.6 \mathrm{~cm}$ in height, which appeared in two of the three high impact shoreline plots. One of the April 2001 elevation plots recorded some of this lateral erosion, but average losses shown in fig. 25 are likely underestimated because the plot showing the greatest erosion was destroyed before the April reading, and the second plot showing lateral erosion could not be read in August 2001.

The high rate of elevation loss recorded in the high impact interior plots (the former shrimp pond; fig. 26) was also related to sediment compaction. Like the high impact shoreline forest, initial surface stability occurred over the first three and a half months of the study (18-21.5 months after Hurricane Mitch). Initial stability was followed by elevation loss, presumably due to compaction and subsidence because marker horizon plots were not systematically eroded away (fig. 24). However, any inferences into recovery trajectories of these plots need to be considered in light of the degree of hydrological alteration to this area, which included levees and other water control structures, and initial grading (for shrimp pond development) of the surface prior to establishment of the field plots. Furthermore, after January 2001, this area was fully restored to a shrimp pond, with restricted hydrologic connection to the estuary. Although elevation change was positive $\left(0.46 \mathrm{~cm} \mathrm{yr}^{-1}\right.$; fig. 26$)$ at the four remaining impact $\times$ zone combinations, sediment compaction played an important role in elevation dynamics at 
some of these sites as well. For example, in the medium impact shoreline forest, the low rate of elevation gain compared to accretion $\left(1.42 \mathrm{~cm} \mathrm{yr}^{-1}\right)$ suggests that rapid compaction of unconsolidated sediment deposits occurred in this point bar environment. In contrast, there was no compaction of the $90 \mathrm{~cm}$ thick deposit in the medium impact interior forest 18-33 months after deposition. This thick storm deposit located in the low-frequency flooded interior dwarf forest apparently consolidated (dried out) prior to initiation of our field sampling 18 months after the storm. The underlying substrate of the dwarf forest was apparently well consolidated as well.

\section{Discussion}

Each mechanism of hurricane impacts (e.g., winds, wave-related shoreline erosion, burial by beach sand, and burial by eroded upland sediments) caused immediate mangrove mortality in the high and medium impact zones. At some sites, nearly the entire forest was killed. The impact of Hurricane Mitch on the long-term sustainability of sediment elevation of the mangrove forests differed importantly among impact mechanisms (i.e., among the three study sites) and impact intensity, although the impact was not always consistent across shoreline and interior forests at a site. Hence, the implications for mangrove sustainability under future sea-level predictions also differed importantly among impact types, impact intensities, and shoreline and interior forests.

\section{Bay Islands, Honduras}

Nearly three years after the passage of Hurricane Mitch, the mangrove forest at Mangrove Bight remains a ghost forest of dead trees. There has been essentially no 
recolonization by mangrove propagules (one sapling, Hensel and Proffitt, 2002), no inorganic sediment deposition, except for a small amount of sediment reworked from within the interior forest, and the substrate is collapsing from decomposition of the highly organic mangrove peat. Without inorganic sediment input or renewed root production, the elevation of the Guanaja mangrove forests will continue to decrease (fig. 19). Model simulated rates of elevation change indicate that elevation loss was initially very rapid but slowed to approximately $1 \mathrm{~cm} \mathrm{yr}^{-1}$ after all the highly labile organic matter decomposed. In addition, it should be noted that predicted increases in sea-level rise would increase the rate of wetland elevation loss simulated here. In this simulation, we used only the current rate of sea-level rise $\left(0.15 \mathrm{~cm} \mathrm{yr}^{-1}\right)$, as it is expected that some form of restoration will occur at the Guanaja site in the near future due to the lack of natural regeneration.

This model does not predict the elevation at which revegetation would be impossible due to flooding stress, but rather only predicts the rate of elevation loss. Furthermore, the situation is complicated by the uncertainties surrounding the actual elevation of these sites relative to mean sea level. In any event, shallow subsidence rates approaching $1 \mathrm{~cm}$ $\mathrm{yr}^{-1}$, as measured and simulated here, are rapid, and a cause for concern. If the habitat converts from high intertidal forest to low intertidal mudflat, it will be very difficult to restore the elevation needed to support a mangrove forest. Wanless and others 1994 reported that in southwest Florida, USA, mudflats developed, apparently as a result of peat collapse, from mangrove forests that died as a result of the 1935 Labor Day Hurricane. The mud flats subsequently expanded in size as a result of mangrove mortality 
following the 1947 hurricane and Hurricane Donna in 1960 and still exist today. Natural recolonization has not occurred in these mudflats after more than 60 years, despite a plentiful source of propagules in the immediate vicinity. For a rapidly subsiding freshwater forested wetland in Louisiana, USA (Rybczyk and others, 1998), a simulation model showed that above a critical sediment elevation at which plants could survive and regenerate, the combined accretion of organic matter and mineral matter had a synergistic effect on elevation which allowed the wetland to keep pace with high rates of relative sea-level rise. Below the critical sediment elevation, however, the elevation decreased rapidly and additional mineral inputs had much less of an overall effect on wetland elevation change. Thus, remediation measures must be taken to stop and reverse sediment elevation losses in the forest at Mangrove Bight. Given that inorganic sediment input to these forests is low and that natural recolonization is not occurring or is limited, mangrove vegetation will have to be reestablished through plantings to renew root production and restore sediment elevation in the dead forests. However, it is unclear whether current elevations and soil conditions are suitable to support seedling survival.

The sustainability of the mangrove forests at Mangrove Bight has implications for the health of the seagrass communities located immediately adjacent to them. The extensive seagrass beds, located as close as $5 \mathrm{~m}$ from the mangrove shoreline, survived the passage of Hurricane Mitch, and as of January 2000, had not undergone any significant burial by mangrove sediments (Michot and others, 2002), perhaps due to their predominately organic composition and the maintenance of soil integrity in the shoreline zone. 
However, loss of the mangrove buffer zone might eventually allow upland sediments to reach seagrass beds.

The shoreline forest on the north shore of Roatan (medium impact site) survived the passage of Hurricane Mitch with little or no mortality (Hensel and Proffitt, 2002) and our data indicate that sediment elevation of this forest remained stable three years after the storm. Indeed, the sediment and elevation dynamics of this forest were identical to those of the low impact forest on the south shore of Roatan. No remediation measures are needed for this impacted forest. In contrast, parts of the interior forest on the north shore of Roatan suffered severe mortality as a result of wind and storm surge impacts from the hurricane (Hensel and Proffitt, 2002). The sediment elevation of this forest collapsed at the same rate as the interior forest on Guanaja. Currently much of the dead zone remains flooded most of the year (with a combination of both rain and sea water), because the hydrological connection to the shoreline is restricted by the low-lying marl ridge. Consequently, as sediment collapse continues, parts of this forest may eventually convert into a permanent lagoon. Regrowth and recovery is apparent in the dead zone (Hensel and Proffitt, 2002), but results of this study indicate that soil formation is not keeping pace with soil oxidation and compaction. Therefore, remedial plantings should be undertaken soon because, if elevation losses continue, a critical point may be reached where flooding stress may inhibit successful restoration in this area. Like Mangrove Bight on Guanaja, the sustainability of this mangrove forest has implications for the health of the seagrass communities located immediately offshore. These seagrass beds survived the passage of Hurricane Mitch, and as of January 2000, had not undergone any 
significant burial by mangrove sediments (Michot and others, 2002). However, loss of the mangrove buffer zone might eventually allow upland sediments to reach seagrass beds. The long-term survivability of the larger Santa Elena mangroves, however, appears secure.

\section{Punta de Manabique, Guatemala}

Landward beach erosion of the Caribbean shoreline by storm-induced wave action overturned mature mangrove trees located immediately behind the barrier beach and placed the forest within an exposed shoreline. The eroded beach sand was carried inland by the storm surge and buried some additional mangrove trees. The buried trees showed signs of physiological stress (e.g., partial loss of foliage), but many were still alive three years after the storm (Hensel and Proffitt, 2002). Overall trends in recovery of sediment elevation (and hence the mangrove forest) are not clear given the highly dynamic nature of these sandy sediments. The $60-120 \mathrm{~cm}$ storm deposit is gradually eroding away, but recurring storms can rework sediments resulting in additional sediment deposits. However, it is probable that if the new shoreline remains in its current location and is not reestablished at its more seaward prestorm position, this stressed mangrove forest may be lost under a regime of repeated accretion and erosion events, typical of sandy shorelines in this highly dynamic setting.

\section{Gulf of Fonseca}

The mangrove forests buried by sediments eroded from the Choluteca watershed differed in their survival and poststorm elevation dynamics, depending on impact intensity and 
position in the intertidal zone (shoreline vs. interior). Thus, the sustainability of sediment elevation in relation to sea-level rise also differed among the forests because of the different amounts of elevation capital provided by the storm deposits. For example, the shoreline forest buried by $7-25 \mathrm{~cm}$ of sediment (medium impact) exhibited little mortality 18-33 months after the catastrophic flood (i.e., there were few dead standing trees; Hensel and Proffitt, 2002). This forest is experiencing high rates of shallow subsidence caused by compaction of the storm deposit but not collapse of the mangrove peat, as is occurring at Guanaja on the Caribbean coast. Overall, there was a positive slope of vertical accretion and elevation change in this forest. Hence, the current elevation of this healthy forest relative to sea level has been enhanced by the storm deposit, and despite the high rate of compaction of the storm deposit and recently reworked sediments, sediment elevation will likely remain stable relative to sea level for the foreseeable future.

In contrast, the shoreline forest buried by $36-50 \mathrm{~cm}$ of sediment (high impact) and the interior forest buried by 78-97 $\mathrm{cm}$ of sediment experienced extensive although not complete mortality (Hensel and Proffitt, 2002). The interior forest is not losing elevation while the shoreline forest is losing elevation rapidly (nearly $2.1 \mathrm{~cm} \mathrm{yr}^{-1}$ ) as a result of compaction of the poorly consolidated storm deposit, and likely also the underlying organic mangrove peat. Despite the high rate of elevation loss in the shoreline forest, the sediment elevation of both forests relative to sea level has been enhanced by the storm deposit to the extent that they will not be vulnerable to submergence for a long time. Rather, the sustainability of these stressed forests likely depends on their ability to restore root biomass near the new sediment surface, which will bind sediments, enhance both 
inorganic soil retention and organic soil formation, and allow for gas exchange to the roots. McKee and McGinnis (2002) reported there was little to no fine root production within these thick sediment deposits two years after the storm. Trees of the white mangrove (Laguncularia racemosa (L.) Gaertn.f.) appear to be recovering well (Hensel and Proffitt, 2002), although these mangroves may experience greater salinity stress at the higher, less flooded elevation. There is also evidence of red mangrove seedling establishment (Rhizophora mangle L) in the shoreline forests (Hensel and Proffitt, 2002). Despite signs of forest recovery, chronic effects of sediment burial and reworking will remain for some time. Surviving mangroves and new recruits face altered and continuously changing sediment elevation conditions, which may slow down the recovery process. The reworking (repeated erosion and deposition) of this storm deposit and the possible return to prestorm elevations will be a gradual process, if it occurs at all. Whether or not these forests will survive remains to be seen. Can the forests fully recover if there is no erosion? If there is erosion, will the forests be able to adapt to the changing elevations?

The upper reaches of the Conchalitos estuary represent the most severe of the continuum of Hurricane Mitch-induced sedimentation impacts in the Gulf of Fonseca. Damaged mangrove forests and unstable, reworked sediments also were apparent in the El Pedregal estuary to the south, and the Chismuyo Bay to the north. Results of this study suggest that chronic sedimentation impacts remain in the larger Gulf of Fonseca despite signs of natural mangrove forest recovery. 


\section{Acknowledgments}

The authors would like to extend special acknowledgments to the following people, without whose collaboration this project would not have been possible:

Honduras:

Jeff Phillips (USAID, HN) and Adrian Oviedo (SERNA, HN), for untiringly and enthusiastically coordinating and supporting all of in-country operations, including personnel, logistics, and coordination with other programs, as well as scientific and field support; Gloria Wilkie (USAID, HN), Elsy Phillips (USAID, HN) and John Walkey (Raytheon), who, along with Jeff and Adrian, provided invaluable assistance to all incountry coordination and logistical support; Sherry "Pilar" Thorn (Universidad Autonomca de Honduras), for scientific support, in-depth local knowledge and logistical support at the beginning of the program; Gerardo Pavon (USAID, HN) and Jose Mario Estrada (USAID, HN), for untiring assistance with transportation in Tegucigalpa and the Gulf of Fonseca, for assistance with local contacts and knowledge of the area and its history; Siyyid Romero and Kenya Arollo (ESNACIFOR, HN), for in-depth knowledge of Guanaja and Mitch-associated damage and recovery, and for their much-appreciated logistical support and assistance in the field; Cifredo Salinas and Estela Miller (Unidad Municipal Ambiental, Guanaja, HN), for logistical support in Guanaja; Claude Buffet, Jacques Grelot, Isabelle Valade and Pedro Portillo (PMAIB, Consorcio Safege-SogreahMoncada y Moncada, HN), for very useful collaboration with the effort in the Bay Islands and providing much-appreciated logistical support in Roatan; Patricia Midence (Universidad Autonoma de Honduras) for assistance with data-collecting in the field 
(Gulf of Fonseca); Carlos Manoliba ("Caman") and Juan Alberto Vaca, local fishermen in San Lorenzo, for their reliable assistance with logistics in field operations (Gulf of Fonseca), for valiant help in the field and willingness to share extensive knowledge of the area; Edas Muñoz (PROARCA/Costas, HN), for helping support this effort; Hector Corrales (ANDAH, HN), for kind collaboration at the beginning of the project; David Jaen (Ambioconsult, HN), for field assistance.

\section{Guatemala:}

FUNDARY (GT) and in particular Mario Dary, Estuardo Herrera, Erwin Herdocia, Fidel Santos, Rebecca Haacker, Blanca Rosa, Ana Beatrice, Carlos and Brenda for their enthusiastic support of the project in Punta de Manabique, for logistical support and scientific and historical knowledge; Segio and Luis (EcoHotel El Saraguate, Punta de Manabique), for valuable logistical and field support.

\section{USA:}

Tommy McGinnis II, for his assistance throughout all phases of this work, including data interpretation; Lawrence Handley (USGS) and Jesse Thibodeaux (Johnson Controls, Inc.), for providing us with useful geographic products; Alejandro Arrivillaga (Johnson Controls, Inc.), for his invaluable assistance throughout all phases of the study in Guatemala, including materials, transportation and other logistics, in-depth local knowledge and field work; Andrea Anteau (USGS) and Patti Faulkner (LA Natural Heritage Program), for assistance with the field effort in Honduras and Guatemala; Nancy Zeigler and Debbie Norling (USGS) for coordinating foreign travel. 


\section{Literature Cited}

Allen, J. R. S., 1990, The formation of coastal peat marshes under an upward tendency of relative sea-level: Journal of the Geological Society of London v.147, p.743-747.

Cahoon, D. R., and Lynch, J. C., 1997, Vertical accretion and shallow subsidence in a mangrove forest of southwestern Florida, USA: Mangroves and Salt Marshes, v. 1, p. 173-186.

Cahoon, D. R., Lynch, J. C., Perez, B. C., Segura, B., Holland, R., Stelly, C., Stephenson, G., and Hensel, P., 2002, High precision measurement of wetland sediment elevation: II. The rod surface elevation table: Journal of Sedimentary Research, v. 72, n. 5, p. 734-739.

Callaway, J. C., Nyman, J.A., and DeLaune, R. D., 1996, Sediment accretion in coastal wetlands: a review and a simulation model of processes: Current Topics in Wetland Biogeochemistry, v. 2, p. 2-23.

Chen, R. and Twilley, R. R., 1999, A simulation model of organic matter and nutrient accumulation in mangrove wetland soils: Biogeochemistry, v. 44, p. 93-118.

Day, J. W., Rybczyk, J., Scarton, F., Rismondo, A., Are, D., and Cecconi, G., 1999, Soil accretionary dynamics, sea-level rise and the survival of wetlands in the Venice Lagoon: a field and modeling approach: Estuarine, Coastal and Shelf Science, v. 49, p. 607-628. 
DeSomviele, B., 1999, Étude de la reforestation de l'île de Guanaja après l'ouragan Mitch: Paris, France, École Nationale du Génie Rural, des Eaux et des Forêts, p. 42.

Ellison, J. C., 1998, Impacts of sediment burial on mangroves: Marine Pollution Bulletin, v. 37, p. 420-426.

Emery, K. O. and Aubrey, D. G., 1991, Sea Levels, Land Levels, and Tide Gauges: New York, N.Y., Springer-Verlag, p. 237.

French, J. R., 1993, Numerical simulation of vertical marsh growth and adjustment to accelerated sea-level rise, North Norfolk, United Kingdom: Earth Surface Processes and Landforms, v. 18, p. $63-81$.

Gornitz, V., 1995, Sea-level rise: a review of recent past and near-future trends: Earth Surface Processes and Landforms, v. 20, p. 7-20.

Hensel, P. and Proffitt, C. E., 2002, Hurricane Mitch: Acute Impacts on Mangrove Forest Structure and an Evaluation of Recovery Trajectories: Reston, Va., U.S. Geological Survey Open File Report, in press.

McKee, K.L. and McGinnis, T.C., II, 2002, Hurricane Mitch: Effects on mangrove soil characteristics and root contributions to soil stabilization, Reston, Va., U.S. Geological Survey Open File Report, in press. 
Michot, T. C., Burch, J. N., Arrivillaga, A., Rafferty, P. C., Doyle, T. W., and Kemmerer, S., 2002, Impact of Hurricane Mitch on seagrass beds and associated shallow reef communities along the Caribbean coasts of Honduras and Guatemala, Reston, Va., U.S. Geological Survey Open File Report, in press.

Mitsch, W. J. and Reeder, B. C., 1991, Modeling nutrient retention of a freshwater coastal wetland: estimating the roles of primary productivity, sedimentation, resuspension and hydrology: Ecological Modeling, v. 54, p. 151-187.

Morris, J. T. and Bowden, W. B., 1986, A mechanistic, numerical model of sedimentation, mineralization and decomposition for marsh sediments: Soil Science Society of America Journal, v. 50, p. 96-105.

Penland S. and Ramsey, K. E., 1990, Relative sea-level rise in Louisiana and the Gulf of Mexico: 1908-1988: Journal of Coastal Research, v. 6, p. 323-342.

Richmond, B., Peterson, S., and Vescuso, P., 1987, An academic user's guide to STELLA: Lyme, N. H., High Performance Systems, p. 392

Rybczyk, J. M., Callaway, J., and Day, J. W., Jr., 1998, A relative elevation model (REM) for a subsiding coastal forested wetland receiving wastewater effluent: Ecological Modeling, v. 112, p. 23-44. 
SAS Institute Inc., 2000, SAS/STAT User's Guide, Version 8, SAS Institute Inc., Cary North Carolina, USA, p. 3908.

Twilley, R. R., Chen, R., and Rivera-Monroy, V., 1999, Formulating a model of mangrove succession in the Caribbean and Gulf of Mexico with emphasis on factors associated with global climate change: Current Topics in Wetland Biogeochemistry, v. 3, p. 119-141.

Wanless, H. R., Parkinson, R. W., and Tedesco, L. P., 1994, Sea level control on stability of Everglades wetlands, in Davis, S. M., and Odgen, J. C., eds., Everglades, the Ecosystem and Its Restoration: Delray Beach, FL St. Lucie Press, , p. 199-222.

Wanless, H. R., Tedesco, L. P., Bischof, B., Risi, J. A. and Smith, T., 1995, Post-event subsidence: a dominating control on mangrove community evolution following major hurricanes, in Abstracts with Programs, 1995 Annual Meeting of the Geological Society of America, New Orleans, Louisiana November 6-9, 1995: Boulder, CO, Geological Society of America, p. 452. 


\section{Appendix}

Relative Elevation Model Methodology.

Model Description. The model utilizes a cohort approach (tracking discreet packages of sediments through depth and time) to simulate sediment dynamics (organic and mineral matter accretion, decomposition, compaction, and belowground productivity). These dynamics produce model-generated changes in sediment characteristics including bulk density, organic matter volume and mass, mineral matter volume and mass, and pore volume. The model yields total sediment height as an output. Sediment height is then balanced with eustatic sea-level rise (ESLR) and deep subsidence, both forcing functions, to determine wetland elevation relative to sea level. The model was programmed using STELLA iconographic modeling software (Richmond and others 1987). An Euler numerical method, with a $? \mathrm{t}=1$ week, was used to solve the finite difference equations generated by the STELLA software. The model consists of three linked submodels or sectors: (1) primary productivity; (2) sediment dynamics; and (3) relative elevation.

Primary Productivity Submodel. There are two state variables in this submodel, leaf (aboveground biomass) and root (belowground biomass). These state variables are a function of one constant, root to shoot ratio (rootmult), and four rates: (1) net primary production (maxnet), (2) leaf litter production during the growing season (llitrateg), (3) leaf litter production at the end of the growing season (llitrated), and (4) root litter production (rlitrate). The simulated organic matter is allocated to the sediment dynamics submodel on the surface 
as leaf and wood litter and within the sediment soil column as root biomass, with the exception that a fraction of leaf litter is exported by tides.

Annual leaf production is simulated as a function of aboveground standing crop. This regression function, originally developed by Chen and Twilley (1999), is derived from datacollected from 17 mangrove forests in Florida, Puerto Rico and Mexico $\left(\mathrm{R}^{2}=0.6\right.$, $\mathrm{P}<.0001)$. The original equation expressed leaf production as a function of basal area, and was modified to:

maxlgrow $=(1.33+(((\mathrm{cwood} / 10000) * 16) * .292)) * 100$

where:

$$
\begin{aligned}
& \text { maxlgrow }=\text { maximum leaf production }\left(\mathrm{g} \mathrm{d} . \mathrm{w} . \mathrm{cm}^{2} \text { year }{ }^{-1}\right) \text { and, } \\
& \text { cwood }=\text { standing crop of wood }\left(\mathrm{g} \cdot \mathrm{d} . \mathrm{w} . \mathrm{cm}^{2}\right)
\end{aligned}
$$

Annual wood production is set to equal leaf production (Rybczyk and others, 1998). Root production is simulated as a constant fraction of (0.75) of wood production (Chen and Twilley, 1999).

Because there is no linked hydrology, hydrodynamics or salt conservation model, elevation relative to sea level acts as a surrogate for salt and flooding stress on vegetation production in the primary production submodel. By employing a simple elevation switching function, simulated aboveground and belowground annual production decrease with decreasing elevation.

Sediment Dynamics Submodel. The sediment dynamics submodel has four state variables, each replicated once in each of 18 soil cohorts: (1) lab_below $w_{n}$, labile organic matter; 
(2) ref_below ${ }_{n}$, refractory organic matter; (3) mineral $_{n}$, mineral matter; and (4) root $n$, live root biomass. Maximum mineral inputs are the only forcing functions in this submodel, as other inputs are model generated. This submodel simulates the decomposition of organic matter, the inputs of mineral matter, the distribution of root biomass, sediment compaction, and the transfer of material from cohort to cohort. These processes are outlined below. Output includes the following sediment characteristics with depth: bulk density, sediment height, organic and mineral matter mass and volume, pore space, and live root mass. Changes within the cohort caused by decomposition and belowground production, which are both a function of modelgenerated depth, are calculated on a weekly basis. Sediment compaction, also calculated weekly, is a function of initial pore space (a forcing function) and the mass of material above a particular cohort. Measurements obtained from soil cores (e.g., bulk density, percent organic matter, and mineral matter) along with measurement of accretion rates derived from horizon markers, all collected as part of this study, provide the data which are used to calibrate the submodel at several points.

Decomposition. The model separates all organic matter into labile and refractory pools, each with its own time-dependent decay rate. Additionally, the labile organic matter decomposition rate for the surface cohort is separate from the labile decomposition rate for the rest of the cohorts (allowing for a distinction from leaf and root labile organic matter). Finally, there is a separate, depth-dependent decomposition rate for deep refractory material. A simple negative exponential (-k) model describes decomposition for each organic matter state variable in each cohort. Required decomposition constants include kdeep, klab, kref, leaf_lab_frac, rlab\%, and klabsurf, all described in table 1. 
Mineral Inputs. Previous models have simulated mineral inputs as a function of wetland elevation (French, 1993; Callaway and others, 1996). A similar approach is used here where mineral inputs are a simple linear function of elevation.

Root Distribution. Although root production (rootprod) is simulated in the productivity submodel, root biomass is distributed to the sediment cohorts in the sediment submodel. We used an adaptation of the distribution algorithm originally developed by Morris and Bowden (1986), where root biomass is assumed to be greatest near the surface and decreases exponentially with depth. A complete description of this function is provided in Rybczyk and others (1998).

Sediment Compaction. Soil compaction is a function of organic matter decomposition and the reduction of sediment pore space (primary consolidation; Penland and Ramsey, 1990). Callaway and others (1996) simulated the compaction of pore space as an asymptotic decrease with depth, bounded by preset minimum and maximum pore space values. We use a modified version of Callaway's algorithm, where the decrease in pore space for a given cohort $\left(\right.$ pore_space $\left._{n}\right)$ is a function of the mass of material above it. Again, a complete description of this function is provided in Rybczyk and others (1998).

Relative Elevation Submodel. Wetland elevation relative to sea level is simulated as the balance between ESLR, deep subsidence, shallow subsidence (including decomposition and compaction), and the accretion of mineral material and organic matter (via root growth 
and litter deposition). The balance between these factors is then added or subtracted from the initial wetland elevation at the start of the simulation. The accretion of mineral matter is modeled explicitly in the sediment dynamics submodel. Inputs of organic matter are simulated in the primary productivity submodel. Shallow subsidence is modeled explicitly with the decomposition and pore space compaction functions described in the sediment dynamics submodel. The combination of inorganic and organic matter accretion, decomposition, and compaction result in the development of a soil column over simulated time. The total height of this column is calculated as the height of the deepest sediment cohort plus the total height of all overlying cohorts. The remaining parameters that affect simulated relative elevation, deep subsidence, and ESLR are entered into the model as forcing functions.

Model Initialization and Calibration. The data required for model initialization are shown in table 1 . Some sediment data (\% organic matter and $\%$ mineral matter) were collected by McKee and others, 2002. However, there were no site-specific data concerning above and belowground standing crop, above ground production, and leaf litter production. Thus, we used literature values from similar sites in Central America, Florida, and Mexico (Twilley and others, 1999; Chen and Twilley, 1999). After initialization the model was run for 200 simulated years for each site to generate a baseline simulated soil column and a "cyber" space for roots to grow. Output from this "presimulation" was then used to initialize the sediment column state variables for model calibration. 
For calibration the model was first run for an additional 100 years using the same rates and constants used for initialization. We then used a step-wise calibration procedure (Mitsch and Reeder, 1991). The primary production submodel was calibrated first, as this model provided critical input to the sediment dynamics submodel. After accurate productivity simulations were obtained, the submodel was linked to the sediment dynamics submodel. The sediment dynamics submodel was calibrated with bulk density, percent organic matter, and percent mineral matter data obtained from sediment cores collected in the field at each site.

Model Applications. Simulating the preimpact forest. The first objective was to simulate a stable preimpact mangrove forest (i.e., a forest with a constant elevation relative to RSLR and a steady to slowly increasing net primary production) that could be used for further simulations. Since there were few site-specific data concerning aboveground production and standing crop and belowground standing crop, we utilized data from the existing literature to supplement sitespecific data.

Hurricane Impact. To simulate the effect of Hurricane Mitch in the interior forest on Guanaja, we first "turned off" the primary production function (maxlgrow) in the preimpact model described above. Additionally, leaf, wood, and root litter functions were modified to reflect the instantaneous death of all primary producers. All leaves were instantaneously pulsed to the forest floor, and all previously live roots were shunted to the soil litter pools (either as labile or refractory material). In contrast, wood was not fluxed instantaneously to surface litter components of the model, but rather, was fluxed at a slower rate to reflect the observations that much of the wood remains as standing dead at the site. 
Since essentially no regeneration has been observed to this point, we ran the impact

model for 10 years (simulated years 1998-2008) with no production inputs. The model was run given current sea-level rise rates of $0.15 \mathrm{~cm} \mathrm{yr}^{-1}$ (Gornitz, 1995). 
Table 1. Initialization parameters for the Guanaja sediment elevation model.

\begin{tabular}{|c|c|c|c|}
\hline$\underline{\text { Symbol }}$ & DESCRIPTION & Fringe & $\underline{\text { Basin }}$ \\
\hline$e s l r \_c$ & sea-level rise & $15.6 \mathrm{~cm} \mathrm{yr}^{-1}$ & $15.6 \mathrm{~cm} \mathrm{yr}^{-1}$ \\
\hline init_elev & initial wetland elevation & $25.3 \mathrm{~cm}$ above MLLW & $37.5 \mathrm{~cm}$ above MLLW \\
\hline kdeep & decomposition rate of deep & 0.0008 week $^{-1}$ & 0.0009 week $^{-1}$ \\
\hline & refractory organic matter & & \\
\hline$k l a b$ & decomposition rate of labile $\mathrm{OM}^{1}$ & 0.020 week $^{-1}$ & 0.025 week $^{-1}$ \\
\hline klabsurf & decomp. rate of surface labile $\mathrm{OM}^{1}$ & 0.30 week-1 & 0.30 week-1 \\
\hline kref & decomp. rate of refractory $\mathrm{OM}^{1}$ & 0.0007 week $^{-1}$ & 0.0009 week $^{-1}$ \\
\hline leaf_lab_frac & labile fraction of aboveground & $50 \%$ & $50 \%$ \\
\hline & biomass & & \\
\hline max_min_in & maximum mineral input & $0.00074 \mathrm{~g} \mathrm{~cm}^{-2}$ week $^{-1}$ & $0.00074 \mathrm{~g} \mathrm{~cm}^{-2}$ week $^{-1}$ \\
\hline poremax & max. fraction of pore space in soil & $94 \%$ & $94 \%$ \\
\hline poremin & min. fraction of pore space in soil & $88 \%$ & $88 \%$ \\
\hline$r l a b \%$ & labile fraction of live roots & $15 \%$ & $15 \%$ \\
\hline root_k & root distribution constant & $0.02 \mathrm{~cm}^{-1}$ & $0.02 \mathrm{~cm}^{-1}$ \\
\hline rootmult & root to shoot ratio & 0.75 unitless & 0.75 unitless \\
\hline surate & local deep subsidence rate & $.0033 \mathrm{~cm} \mathrm{week}^{-1}$ & $.0033 \mathrm{~cm} \mathrm{week}^{-1}$ \\
\hline
\end{tabular}

